\title{
The Influence of the Punched Delta Wings on Flow Pattern and Heat Transfer Characteristic in a Fin-and-Oval-Tube Heat Exchanger
}

\author{
Amnart Boonloi \\ Department of Mechanical Engineering Technology, College of Industrial Technology, \\ King Mongkut's University of Technology North Bangkok, Bangkok 10800, Thailand \\ Correspondence should be addressed to Amnart Boonloi; amnartb@kmutnb.ac.th
}

Received 7 July 2015; Revised 22 September 2015; Accepted 29 September 2015

Academic Editor: Felix Sharipov

Copyright (C) 2015 Amnart Boonloi. This is an open access article distributed under the Creative Commons Attribution License, which permits unrestricted use, distribution, and reproduction in any medium, provided the original work is properly cited.

\begin{abstract}
3D numerical investigations are performed to study the heat transfer, friction factor, and thermal performance of a fin-and-oval heat exchanger with punched delta wings for a range of $500 \leq \mathrm{Re} \leq 2500$ (based on the hydraulic diameter). The influences of the punched angles, $20^{\circ}, 30^{\circ}$, and $45^{\circ}$, flow directions, wing tips pointing downstream and upstream, and pitch ratios, 2, 3, 4, 5, and 6 , are investigated. The results show that the use of the punched delta wings in the fin-and-oval-tube heat exchanger leads to an enhancement in the heat transfer and friction loss as compared to the plain fin for all cases $\left(\mathrm{Nu} / \mathrm{Nu}_{0}\right.$ and $f / f_{0}$ higher than 1$)$. The enhancements of the heat transfer and friction factor are around 1.01-1.22 and 1.37-2.65 times higher than the base case, respectively. The punched delta wings create the vortex flows through the test section that helps enhance the strength of the impinging flow on the tube walls. The impingement of the fluid flow is an important key to augment the heat transfer rate and thermal performance in the heat exchanger.
\end{abstract}

\section{Introduction}

Many turbulators such as wing and winglet are used to enhance the heat transfer rate and thermal performance in fin-and-tube heat exchangers. The turbulators can change the flow structure of the working fluid in the heating system when comparing with the plain fin. The vortex flow or swirling flow is the flow mechanism when using the turbulators that helps to improve the heat transfer rate and performance. Due to the narrow parallel space between the fins, the pressure loss is an important factor which should be considered when installing with various types of turbulators. The investigations on heat transfer, pressure loss, and thermal performance in the fin-and-oval-tube heat exchanger with using turbulators have been widely reported. The numerical study is a method to investigate the effects of turbulators on heat transfer and thermal performance in the fin-andoval-tube heat exchanger. The numerical results can help to describe and report flow structure and heat transfer behavior when using the turbulators in the heat exchanger. The understanding of flow and heat transfer profiles is a way to improve thermal performance of the heating equipment. Moreover, the numerical investigation can help reduce cost and time to study in comparison with the experimental method.

For example, Li et al. [1] numerically studied the flow patterns and heat transfer characteristics in a fin-and-tube heat exchanger with longitudinal vortex generators. The punched and mounted rectangular and delta winglets were used as the vortex generators. They concluded that the use of the vortex generators gives the Nusselt number around 20\% higher than the plain fin. They also reported that the maximum thermal performance is found at the attack angles of $25^{\circ}$ and $45^{\circ}$, respectively, for the rectangular and delta winglets. Gong et al. [2] reported the use of punched rectangular vortex generators in a heat exchanger on thermal performance. They found that the secondary flow and reducing wake region are reasons for enhancing the heat transfer rate and thermal performance. 
Delač et al. [3] investigated with the numerical method for the augmentation of heat transfer rate in a fin-and-tube heat exchanger with vortex generators at $\mathrm{Re}=350-2200$. They presented the effects of the impact angles, $5^{\circ}, 10^{\circ}$, and $20^{\circ}$, and the winglet height. They summarized that the impact angle of $10^{\circ}$ performs the optimum ratio between the enhancing heat transfer rates and the increasing friction loss in the heat exchanger. Lotfi et al. [4] numerically studied various type vortex generators, rectangular trapezoidal winglet (RTW), angle rectangular winglet (ARW), curved angle rectangular winglet (CARW), and wheeler wishbone (WW), in a wavyfin-and-elliptical-tube heat exchanger on flow structures and heat transfer behaviors. The effects of the attack angles, $15^{\circ}$, $30^{\circ}, 45^{\circ}, 60^{\circ}$, and $75^{\circ}$, and width/length aspect ratios, 0.5 and 1.0, were reported. They found that the CARW gives the best thermal performance at a small attack angle, while the RTW provides the optimum thermal performance at a large angle. Gholami et al. [5] presented the influences for rectangular winglet vortex generators with the attack angle of $30^{\circ}$ on heat transfer and pressure drop in a finand-tube heat exchanger for $\mathrm{Re}=400-800$. They claimed that the $30^{\circ}$ wavy rectangular winglet vortex generators can improve the heat transfer rate with a moderate pressure loss penalty. The numerical investigations on the influences of the span angles $30^{\circ}-60^{\circ}$ and transverse locations $2-20 \mathrm{~mm}$ for vortex generators in a plate-fin-and-tube heat exchanger at $\mathrm{Re}=400-1200$ were reported by Jang et al. [6]. He et al. [7] presented the numerical investigations on heat transfer and pressure loss in a fin-and-tube heat exchanger with rectangular winglet vortex generators. They concluded that the longitudinal vortex flow and the impinging flow are important factors to augment the heat transfer rates. They also pointed out that the staggered arrangement of the RWVG can reduce the pressure loss in the heat exchanger by using rectangular winglet vortex generators. Saha et al. [8] studied the influences of rectangular delta winglets with commonflow-up and common-flow-down arrangements in a platefin heat exchanger on thermal performance with numerical method. They summarized that the RWP provides higher heat transfer rate than the DWP. Du et al. [9] analyzed the effects of punched longitudinal vortex generators in a wavy-finned-flat-tube heat exchanger. They presented that the optimum thermal performance is found at the attack angle of $25^{\circ}$ when using the delta winglet pairs. Huisseune et al. [10] investigated performance evaluations in a louvered fin heat exchanger by using punched delta winglet vortex generators. They found that the phenomena, reducing tube wakes, swirling flow, and vortex flow, which were created by the punched delta winglet vortex generators, can help to improve heat transfer rate and performance. Li et al. [11] found that the use of longitudinal vortex generators in a slit fin-and-tube heat exchanger provides the thermal enhancement factor around $4.2 \%$ higher than the base type heat exchanger. Lemouedda et al. [12] studied the effects of the attack angles for delta winglet vortex generators in a plate-fin-and-tube heat exchanger with $\mathrm{Re}=200-2000$ based on the inlet height. They also compared the numerical results of the winglet locations between inline and staggered arrangements. Du et al. [13] investigated the heat transfer and thermal performance improvement in a wavy-fin-flat-tube heat exchanger with longitudinal vortex generators. They presented that the values of the Nusselt number and friction factor increase around $21-60 \%$ and $13-83 \%$, respectively, for $\mathrm{Re}=1500-4500$. Chu et al. [14] numerically studied flow topologies, heat transfer profiles, and performance improvement for a fin-and-oval-tube heat exchanger with longitudinal vortex generators at $R e=500-2500$. They reported that the heat transfer and pressure loss are around $13.6-32.9 \%$ and $29.2-40.6 \%$ higher than the base case, respectively. They also stated that the best thermal performance is found at the attack angle of $30^{\circ}$, with downstream arrangement with two tube rows. Joardar and Jacobi [15] carried out study on the heat transfer augmentation by using winglet vortex generators in a plain-fin-and-tube heat exchanger for $\operatorname{Re}=220-960$. They indicated that the augmenting heat transfer rate is around $16.5-44 \%$ and $19.9-68.8 \%$ for single row and three rows of the winglets, respectively. Li et al. [16] investigated thermal performance in a fin-and-tube heat exchanger with radiantly arranged winglets around the tubes. They claimed that the use of the winglet leads to a reduction in the wake regime behind the tube. Tian et al. [17] analyzed punched delta winglets for both inline and staggered arrangements in a wavy-fin-andtube heat exchanger with numerical method. They concluded that $j$ factor is around $13.1 \%$ and $15.4 \%$ for the staggered and inline arrangements, respectively. Lawson and Thole [18] presented heat transfer augmentations in a louvered-fin-andtube heat exchanger with delta winglets. They found the enhancements on the heat transfer rate and pressure loss were around $47 \%$ and $19 \%$, respectively.

From the foregoing review, we found that the enhancements of heat transfer and thermal performance in fin-andtube heat exchangers with winglet type vortex generators has been widely reported. The winglet vortex generators can help generate the vortex flow or swirling flow through the test section which leads to increasing the heat transfer rates. However, the use of the winglet vortex generators not only increases the heat transfer rate but also increases the pressure loss. In current investigation, the punched delta wings are used in a fin-and-oval-tube heat exchanger to enhance the heat transfer rate and performance. The use of the punched delta wings is expected to reduce the pressure loss in the heating system in comparison with the winglet vortex generators. The punched delta wing angles, $20^{\circ}, 30^{\circ}$, and $45^{\circ}$, flow directions, wing tips pointing downstream and upstream, and pitch ratios, $2,3,4,5,6$, are investigated numerically for $\mathrm{Re}=500-2500$ based on the hydraulic diameter of the heat exchanger.

\section{Computational Domain}

Figures $1(\mathrm{a})$ and $1(\mathrm{~b})$ present the fin-and-tube heat exchanger with the punched delta wings for single fin plate and three fin plates, respectively, while the details of the punched delta wings are displayed in Figure 1(c). The delta wings are punched from the fin surface with different punched angles: $20^{\circ}, 30^{\circ}$, and $45^{\circ} . L$ is the computational domain length equal to $64.4 \mathrm{~mm}$. The influences of $a / H$ or PR, $2,3,4,5$, and 6, are presented for Reynolds number, $R e=500-2500$, 


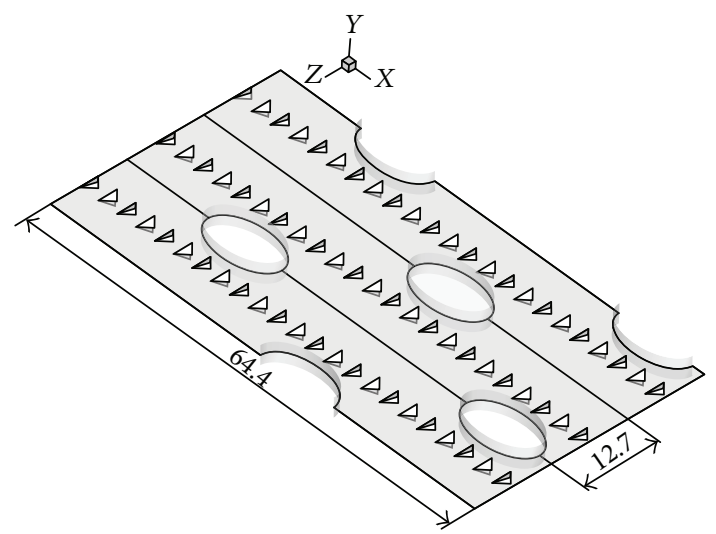

(a)

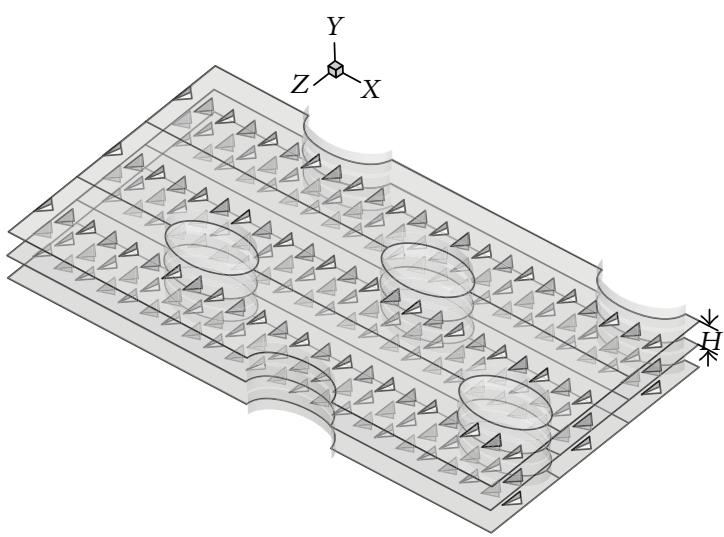

(b)
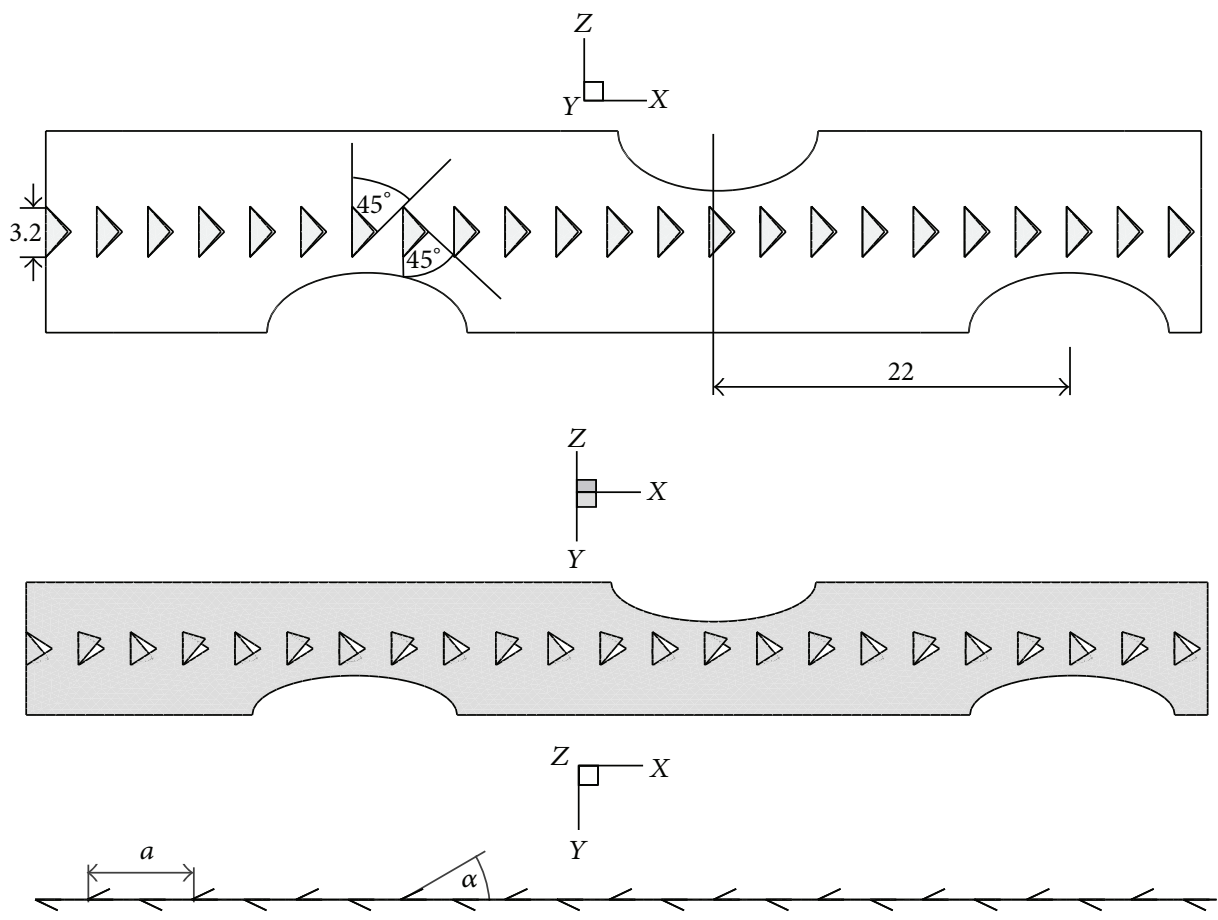

(c)

FIGURE 1: (a) Fin-and-oval-tube heat exchanger with the punched delta wings (single fin plate). (b) Fin-and-oval-tube heat exchanger with the punched delta wings (three fin plates). (c) Details of each fin.

based on the hydraulic diameter $\left(D_{h}\right)$ of the fin-and-ovaltube heat exchanger. The wing tips are set on pointing both downstream and upstream in this investigation. The smooth entrance regime of the computation domain is around $10 \mathrm{H}$ to maintain the inlet velocity uniformity and the domain is extended by $30 \mathrm{H}$ at the exit regime to ensure a recirculationfree flow there. The parameters of the computational domain are displayed in Table 1.

\section{Boundary Condition and Mathematical Foundation}

The fluid flow and heat transfer are assumed to be a steady state. The air flow is laminar flow because of the low velocity of the air at inlet and small fin pitch. Conduction through the fin is taken into account by solving the heat conduction equation. Constant fluid properties and incompressible condition are set for the working fluid. The boundary conditions are presented as follows:

(i) At entry regime, uniform velocity and temperature boundary conditions are used in the current computational domain.

(ii) Pressure outlet condition is set at the outlet of the exit extended region.

(iii) Symmetry condition is used for left-right and the upper-lower zones of the computational model. 
TABLE 1: Parameters of the computational domains.

\begin{tabular}{lcc}
\hline Parameter & Symbol/unit & Value \\
\hline Channel height & $H / \mathrm{mm}$ & 3.2 \\
Computational domain width & $B / \mathrm{mm}$ & 12.7 \\
Computational domain length & $L / \mathrm{mm}$ & 64.4 \\
Semimajor diameter of oval tube & $R_{a} / \mathrm{mm}$ & 6.28 \\
Semiminor diameter of oval tube & $R_{b} / \mathrm{mm}$ & 3.77 \\
Longitudinal tube pitch & $P_{l} / \mathrm{mm}$ & 22 \\
Spanwise tube pitch & $P_{s} / \mathrm{mm}$ & 25.4 \\
Fin thickness & $F_{t} / \mathrm{mm}$ & 0.33 \\
Fin pitch & $F_{p} / \mathrm{mm}$ & 3.2 \\
Number of tube rows & $n$ & 3 \\
Hydraulic diameter & $D_{h} / \mathrm{mm}$ & 3.63 \\
Wall temperature & $T_{w} / \mathrm{K}$ & 300 \\
Inlet temperatures of air & $T_{\text {in }} / \mathrm{K}$ & 340 \\
Frontal velocity & $u_{\text {in }} / \mathrm{m} \mathrm{s}$ & $1.3-6.5$ \\
\hline
\end{tabular}

(iv) For the fin-and-oval-tube region, no slip condition and constant wall temperature are used for the fin and tube surfaces.

The constant temperatures of $300 \mathrm{~K}$ and $340 \mathrm{~K}$ are set for tube walls and air temperature inlet, respectively. The properties of the testing fluid are set at the average bulk temperature. The velocity of air varies between 1.3 and $6.5 \mathrm{~m} / \mathrm{s}$ or the Reynolds number, $R e=500-2500$, depended on the hydraulic diameter of the fin-and-oval tube heat exchanger.

The governing equations for continuity, momentum, and energy can be expressed as follows:

Continuity equation is

$$
\frac{\partial}{\partial x_{i}}\left(\rho u_{i}\right)=0 .
$$

Momentum equation is

$$
\frac{\partial}{\partial x_{i}}\left(\rho u_{i} u_{k}\right)=-\frac{\partial P}{\partial x_{k}}+\frac{\partial}{\partial x_{i}}\left[\mu\left(\frac{\partial u_{k}}{\partial x_{i}}\right)\right] .
$$

Energy equation is

$$
\frac{\partial}{\partial x_{i}}\left(\rho u_{i} T\right)=\frac{\partial}{\partial x_{i}}\left(\frac{k}{C_{p}} \frac{\partial T}{\partial x_{j}}\right) .
$$

The parameters of interest in the present study are the Reynolds number (Re), friction factor $(f)$, Nusselt number

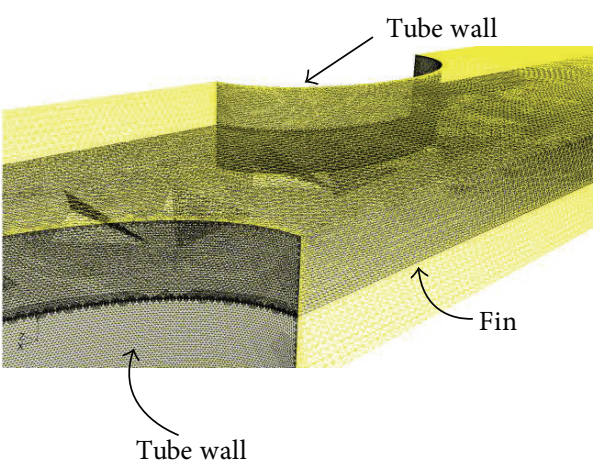

Figure 2: Computational domain.

$(\mathrm{Nu})$, and thermal enhancement factor (TEF) which are expressed as follows:

$$
\begin{aligned}
\mathrm{Re} & =\frac{\rho U_{c} D_{h}}{\mu}, \\
f & =\frac{(2 \Delta p)}{\rho U_{c}^{2}}\left(\frac{D_{h}}{L}\right), \\
\mathrm{Nu} & =\frac{h D_{h}}{k}, \\
\mathrm{TEF} & =\frac{\mathrm{Nu} / \mathrm{Nu}_{0}}{\left(f / f_{0}\right)^{1 / 3}},
\end{aligned}
$$

where $U_{c}, \mu$, and $k$ are the mean velocity in the minimum flow cross section of the flow channel, viscosity, and the thermal conductivity, respectively. $D_{h}$ is the hydraulic diameter, $\Delta p$ is the pressure drop across computation domain, $L$ is the fin length along the flow direction, and $H$ is the height of the channel flow. $\mathrm{Nu}$ and $\mathrm{Nu}_{0}$ are area-average Nusselt number and average Nusselt number of plain fin, respectively.

The governing equations and the boundary conditions are solved by a computational fluid dynamics code. Both the convective and diffusive terms in governing equations for momentum and energy are discretized by second-order upwind scheme. The SIMPLE algorithm has been applied on the coupling among pressure and velocity. The convergence criteria for the velocities and temperature are set to be $10^{-5}$ and $10^{-9}$, respectively.

\section{Numerical Result}

The numerical results for the fin-and-oval-tube heat exchanger with the punched delta wings are divided into four parts: validation of the computational domain, flow visualization, heat transfer characteristic, and performance evaluation. In the validation part, the grid independent test and comparison between the present results, experimental results, and previous results are reported. The flow behavior is presented in terms of streamlines in the transverse plane, while the heat transfer characteristic is shown in forms of temperature distributions and local Nusselt number contours. The variations of the Nusselt number, Nusselt 


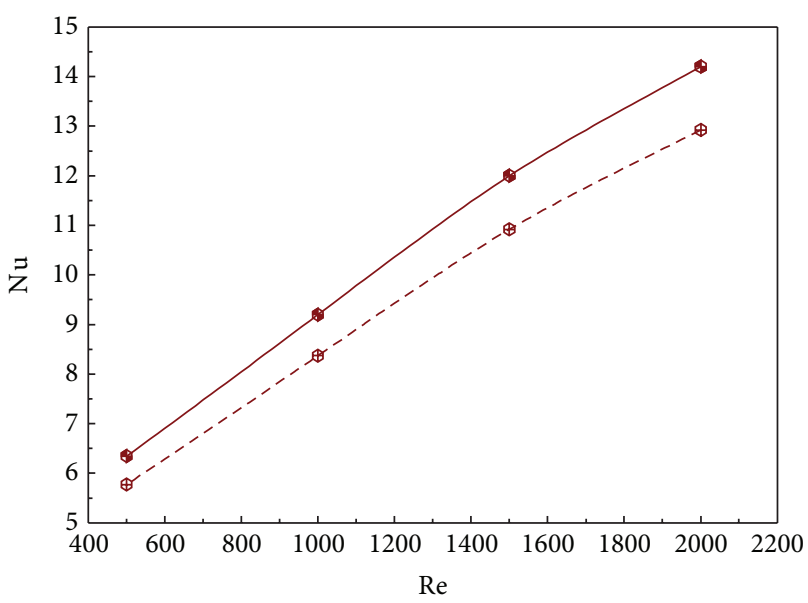

- $\oplus$ - Numerical

- Experimental

(a)

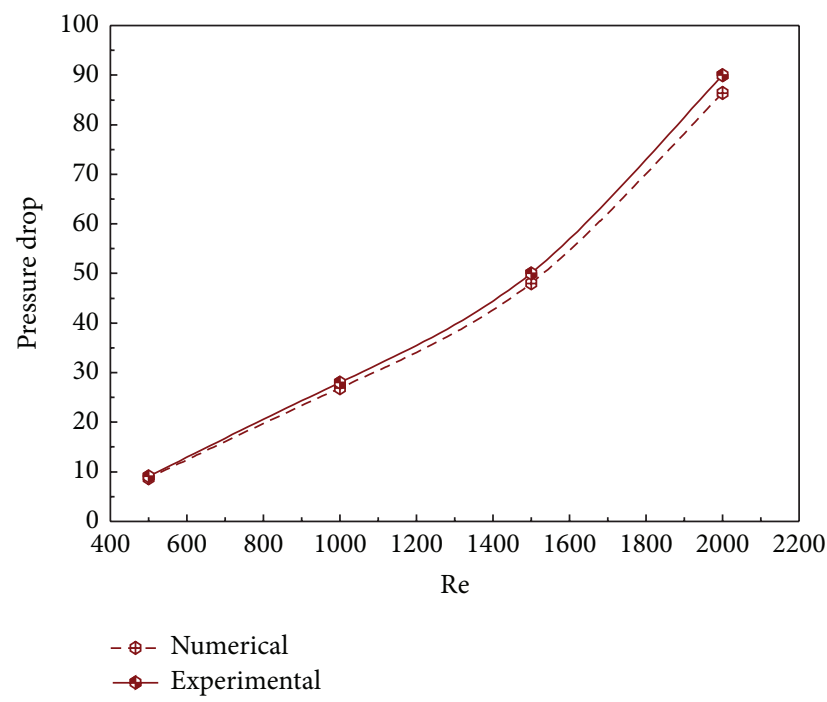

(b)

FIGURE 3: Experimental-numerical comparison for model validations. (a) Nusselt number. (b) Pressure drop.

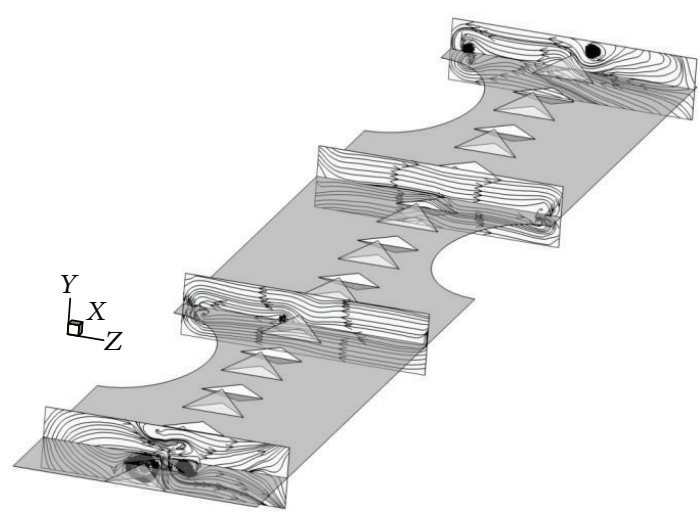

(a)

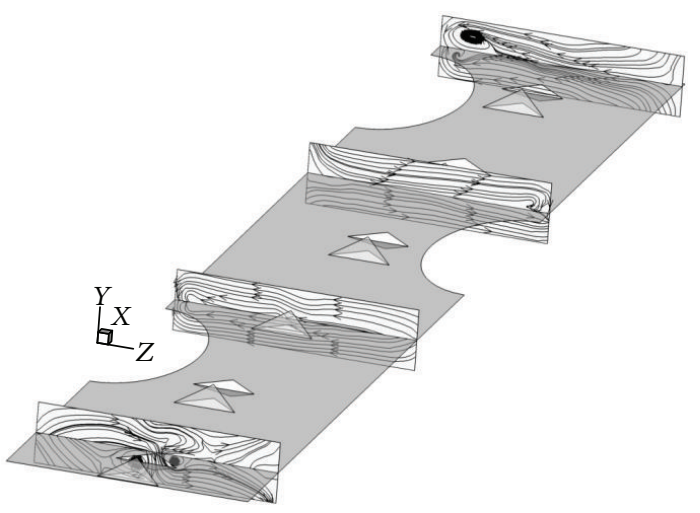

(b)

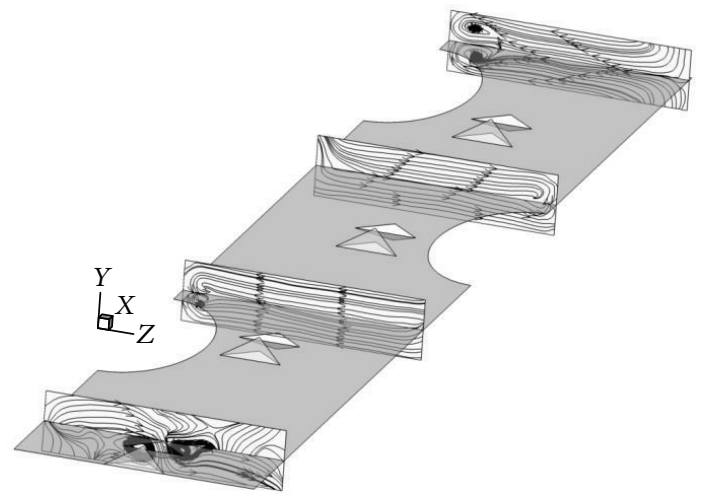

(c)

FIGURE 4: Streamlines in transverse planes for (a) $\mathrm{PR}=2$, (b) $\mathrm{PR}=4$, and (c) $\mathrm{PR}=6$ at $\mathrm{Re}=1500$ and $\alpha=30^{\circ}$ with wing tip pointing downstream. 


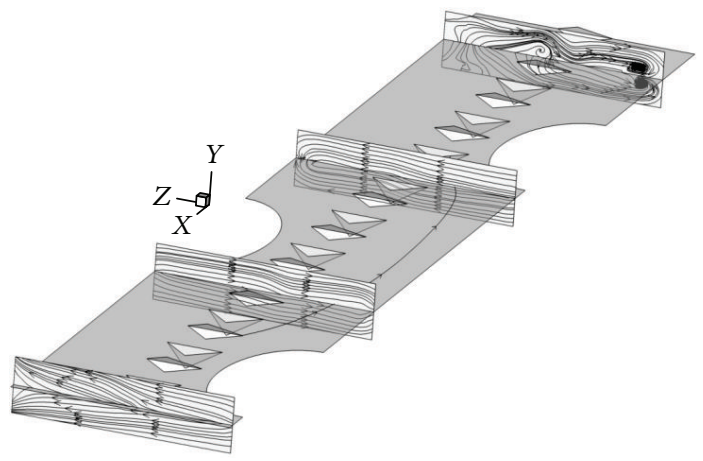

FIGURE 5: Streamlines in transverse planes for $\mathrm{PR}=2$ at $\mathrm{Re}=1500$ and $\alpha=30^{\circ}$ with wing tip pointing upstream.

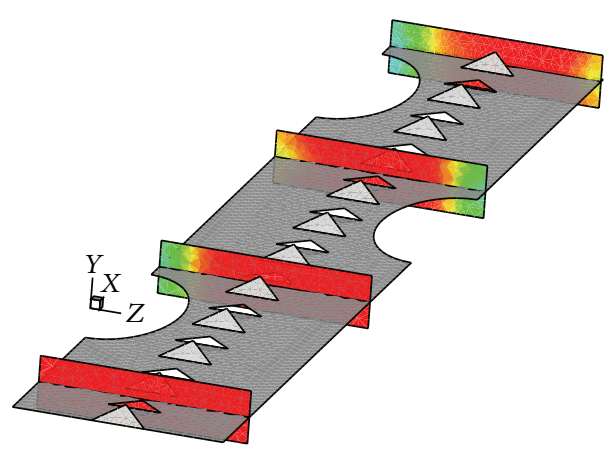

(a)

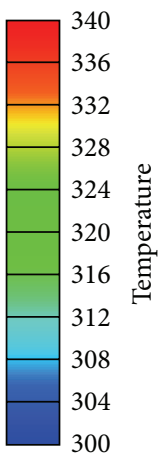

300

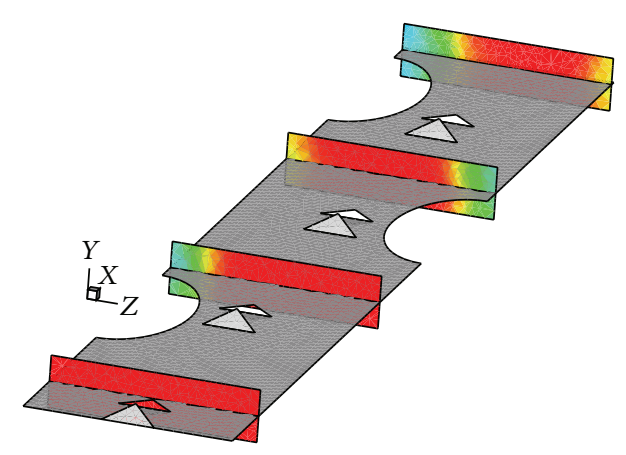

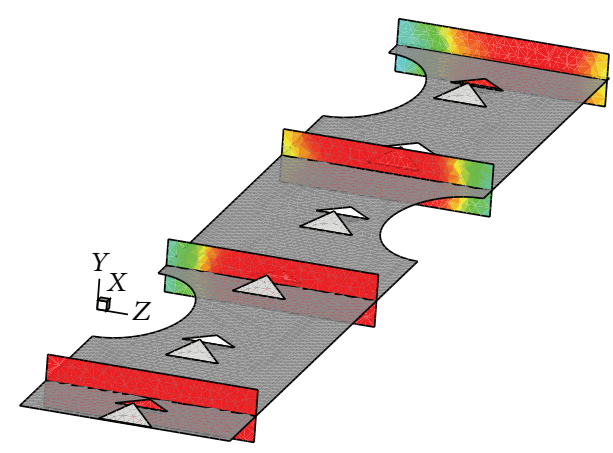

(b)

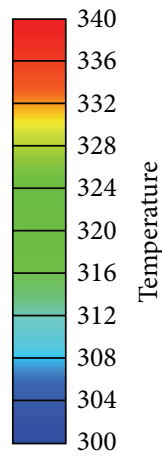

300

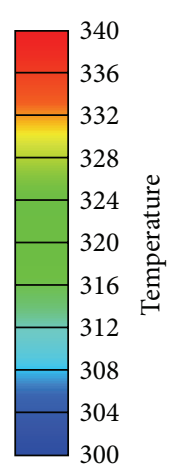

(c)

FIGURE 6: Temperature contours in transverse planes for (a) $\mathrm{PR}=2$, (b) $\mathrm{PR}=4$, and (c) $\mathrm{PR}=6$ at $\mathrm{Re}=1500$ and $\alpha=30^{\circ}$ with wing tip pointing downstream.

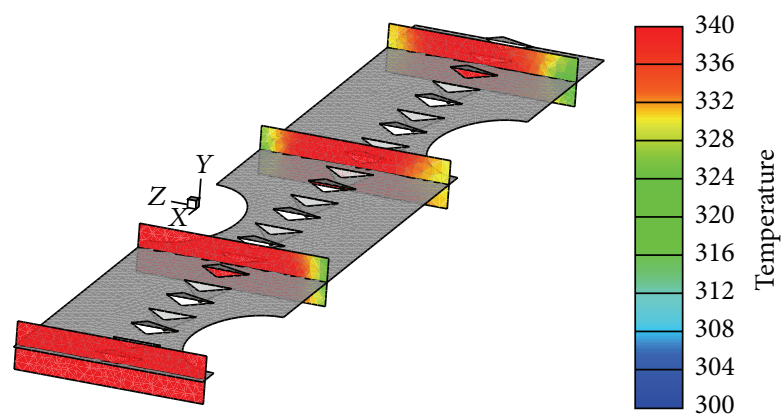

FIGURE 7: Temperature contours in transverse planes for $\mathrm{PR}=2$ at $\operatorname{Re}=1500$ and $\alpha=30^{\circ}$ with wing tip pointing upstream. 


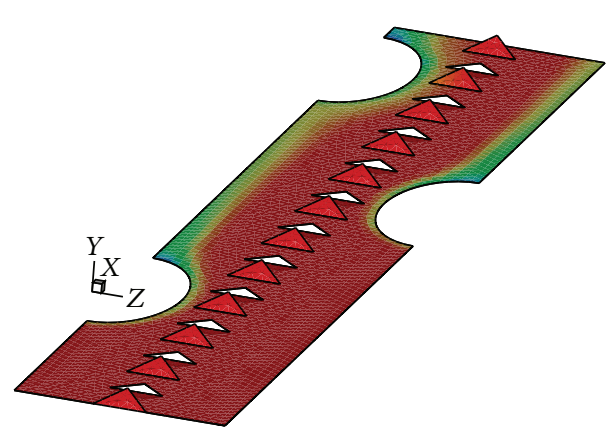

(a)

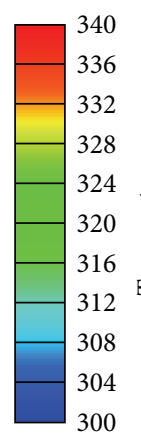

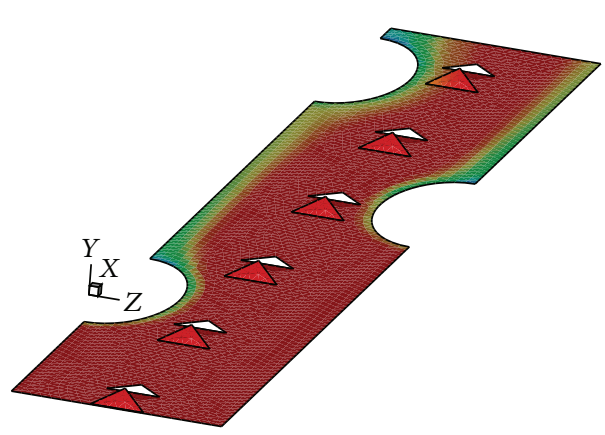

(b)
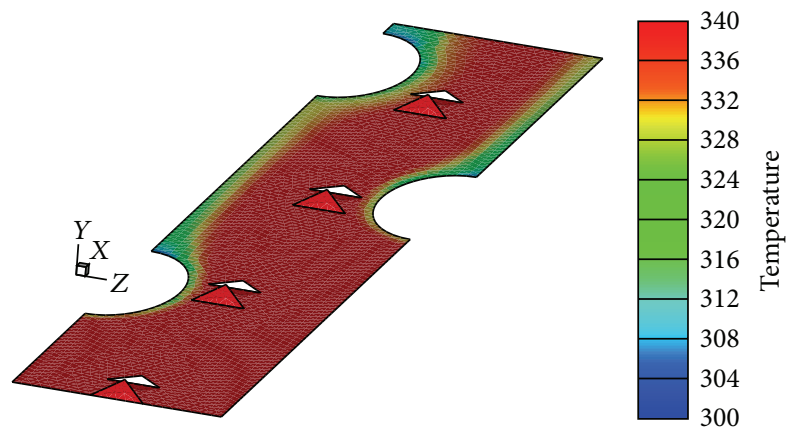

(c)

Figure 8: Temperature contours on the fin surface for (a) $\mathrm{PR}=2$, (b) $\mathrm{PR}=4$, and (c) $\mathrm{PR}=6$ at $\mathrm{Re}=1500$ and $\alpha=30^{\circ}$ with wing tip pointing downstream.

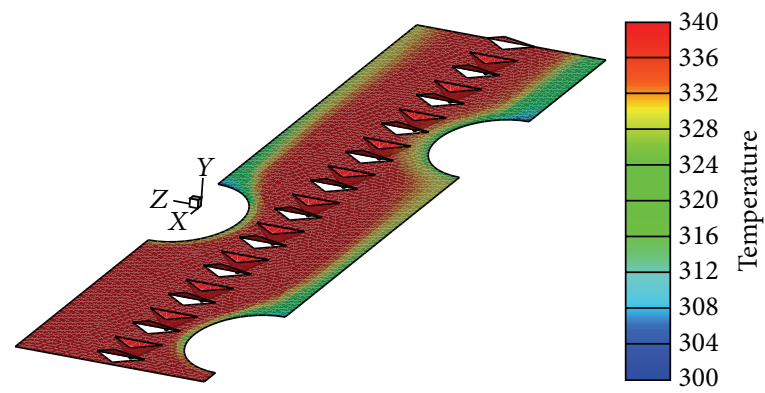

Figure 9: Temperature contours on the fin surface for $\mathrm{PR}=2$ at $\mathrm{Re}=1500$ and $\alpha=30^{\circ}$ with wing tip pointing upstream.

number ratio, friction factor, friction factor ratio, and thermal enhancement factor with the Reynolds number are displayed in the final part, performance evaluation.

\section{Validation of the Computational Method}

The validation of the computational code is a very important part. It is necessary to ensure that the numerical model gives high accuracy and precision. Nonuniform grid is used for the current model. Near the tube wall regime, the grids have high density based on the gradients of temperature, pressure, and velocity. The tetrahedral mesh is used for the computational domain as depicted in Figure 2. The current computational domain is both validated on the number of grid cells and compared with the experimental results. The four sets of grid cells, 270000, 360000, 420000, and 510000, are used in this investigation to verify grid independent test. The numerical results reveal that the increasing grid cells from 360000 to 420000 give relative errors around $\pm 1.5 \%$ and $\pm 1.3 \%$ for Nusselt number and friction factor, respectively. Thus, the number of cells around 360000 is used to optimize the accuracy and the computational time.

The numerical results of the base case (plain fin or no punched wing) are compared with the experimental results [14] on both heat transfer and friction loss of the fin-and-ovaltube heat exchanger in terms of Nusselt number and friction factor, respectively, and are presented in Figures 3(a) and 3(b). The numerical results show a discrepancy of around $9.2 \%$ and $4.0 \%$ for Nusselt number and friction factor, respectively. The good agreement with the experimental results indicates that the computational code is reliable to predict heat transfer characteristic and flow pattern in the fin-and-oval-tube heat exchangers. 


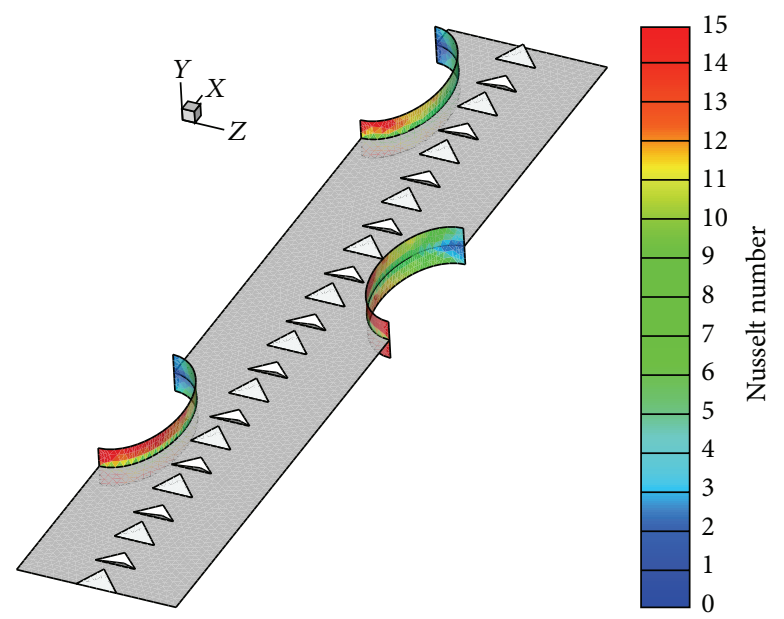

(a)

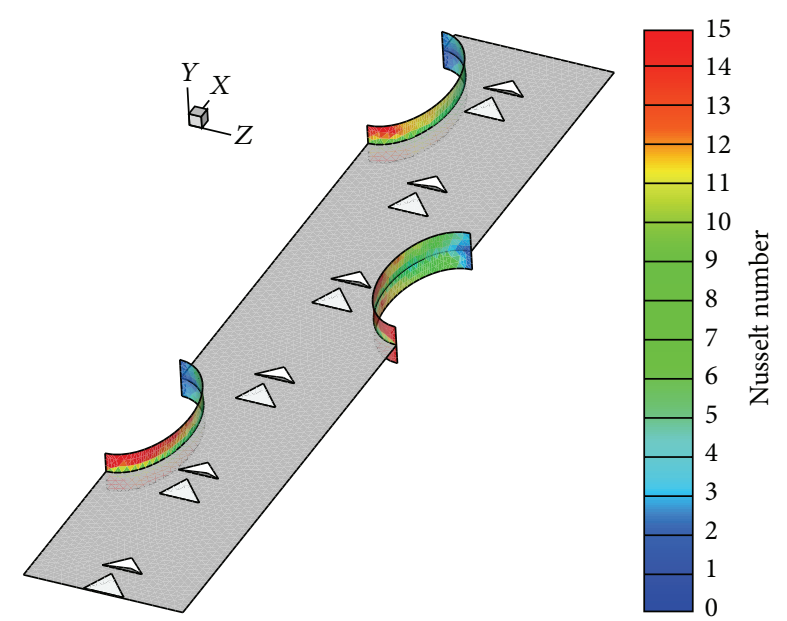

(b)

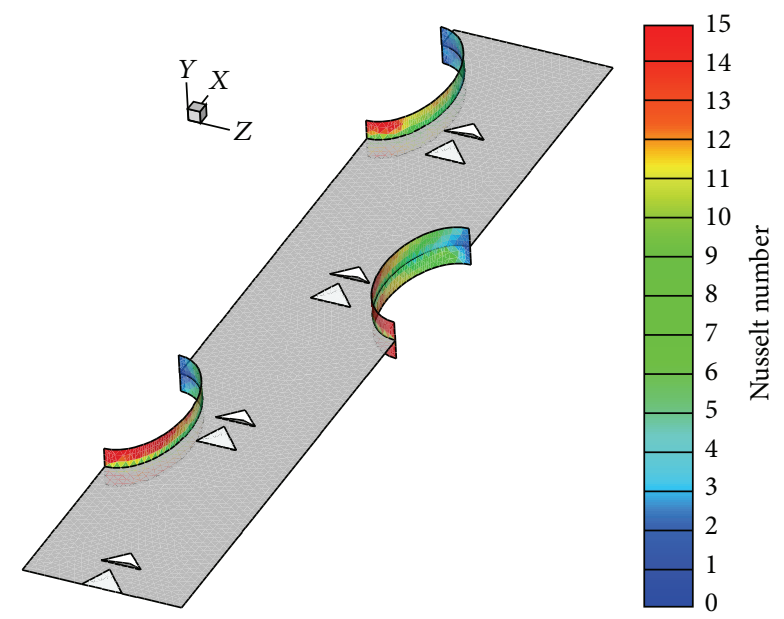

(c)

Figure 10: $\mathrm{Nu}_{x}$ contours on the tube walls for (a) $\mathrm{PR}=2$, (b) $\mathrm{PR}=4$, and (c) $\mathrm{PR}=6$ at $\mathrm{Re}=1500$ and $\alpha=30^{\circ}$ with wing tip pointing downstream.

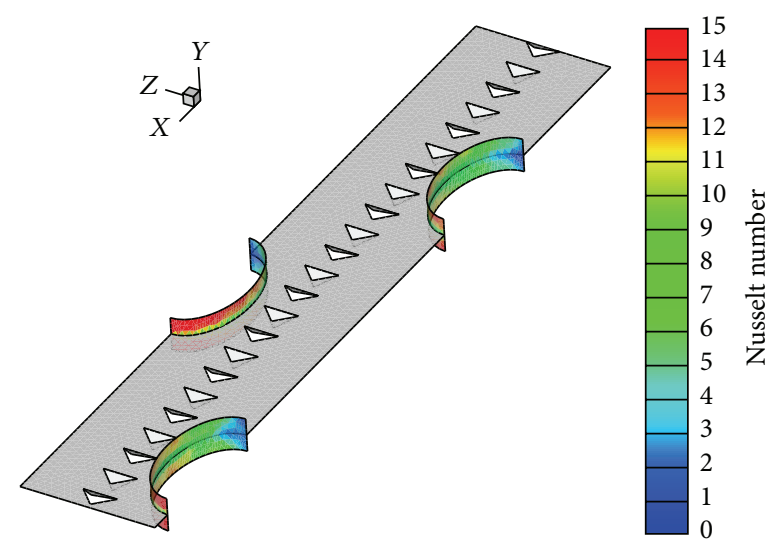

FIGURE 11: $\mathrm{Nu}_{x}$ contours on the tube walls for $\mathrm{PR}=2$ at $\mathrm{Re}=1500, \alpha=30^{\circ}$ and wing tip pointing upstream. 


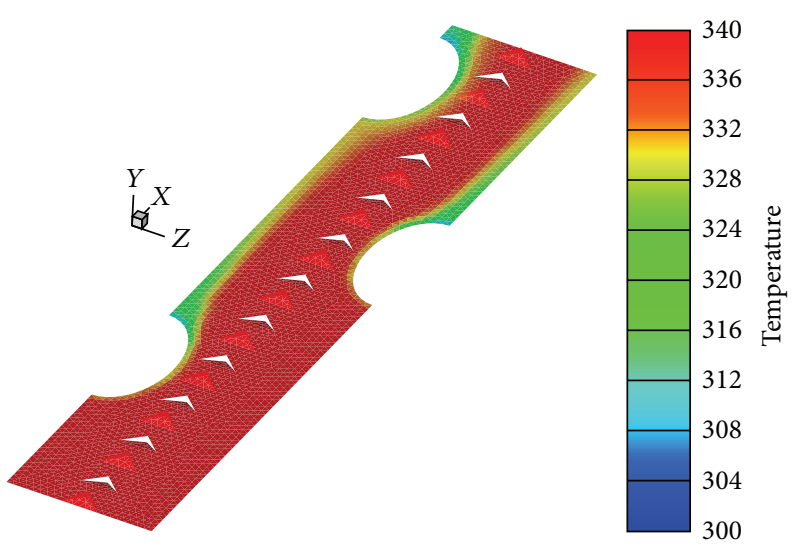

(a)

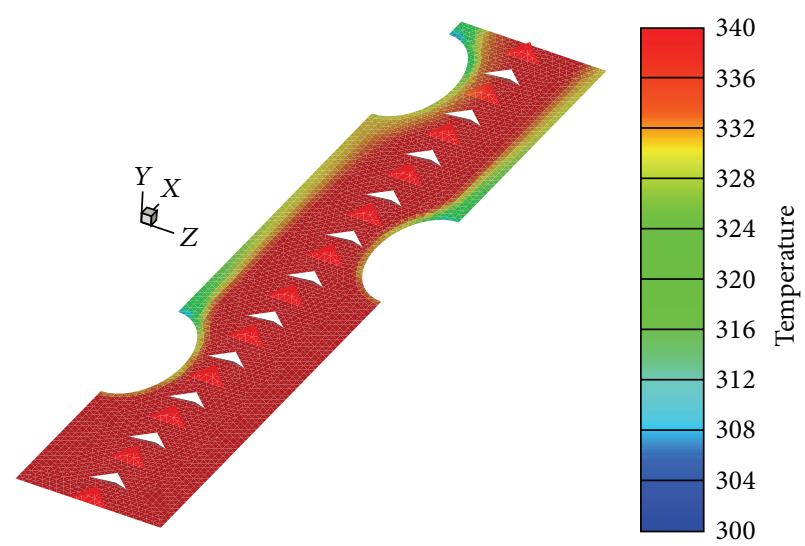

(b)

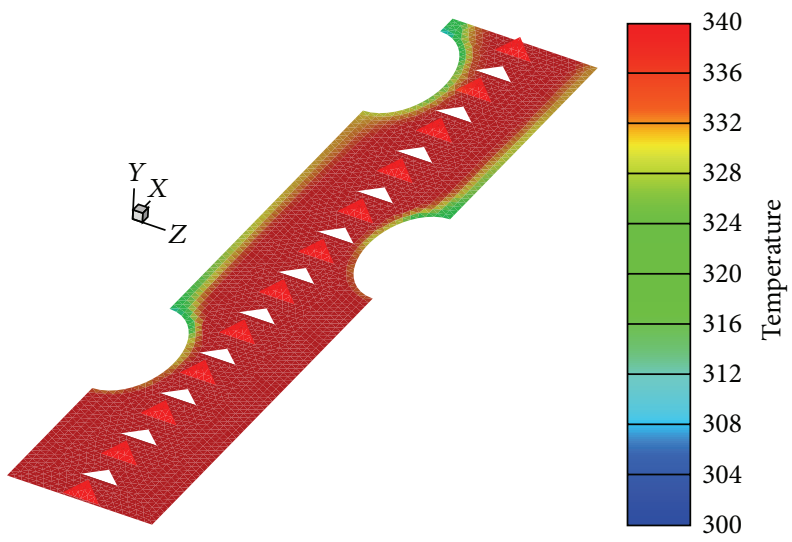

(c)

Figure 12: Temperature contours on the fin surface for (a) $\alpha=20^{\circ}$, (b) $\alpha=30^{\circ}$, and (c) $\alpha=45^{\circ}$ at $\mathrm{PR}=2, \operatorname{Re}=2000$, and $\alpha=30^{\circ}$ with wing tip pointing downstream.

\section{Flow Topology}

Streamlines in transverse planes are used to show the flow pattern of the fin-and-tube heat exchanger with the punched delta wings. Figures 4(a), 4(b), and 4(c) present the streamlines in transverse planes for the punched delta wings in the fin-and-oval-tube heat exchanger at $\operatorname{Re}=1500$ and $\alpha=$ $30^{\circ}$ with wing tip pointing downstream of $\mathrm{PR}=2,4$, and 6 , respectively. In general, the punched delta wings can change the flow structure when comparing with the plain fin. The vortex flows, which generated from the punched delta wings, are clearly seen in the first planes (behind the first delta wing) for all PRs. The structure of the vortex flow in all cases is found to be similar. Moreover, the small vortices are found when the fluid flow passes the oval tubes. These phenomena, vortex flows and small vortices, lead to a better mixing of the fluid temperature between center of the channel and near the tube walls. The better mixing of fluid temperature provides the rise in the heat transfer rates and also helps improve the thermal performance in the fin-and-tube heat exchanger. The use of the punched delta wing not only increases the heat transfer rate but also increases the pressure loss. In addition, $\alpha=20^{\circ}$ and $45^{\circ}$ with wing tip pointing downstream present similar flow pattern as $\alpha=30^{\circ}$ for all PRs.
The streamlines in transverse planes for wing tip pointing upstream at $\operatorname{Re}=1500, \mathrm{PR}=2$, and $\alpha=30^{\circ}$ are displayed in Figure 5. As the figure shows, the punched delta wings can produce the vortex flow similarly as the wing tip pointing downstream. The similar vortex flow and small vortices behind the oval tubes are found in all cases of the wing tip pointing upstream.

\section{Heat Transfers Behavior}

Temperature contours and local Nusselt number contours are used to report the heat transfer behavior for using the punched delta wings in the fin-and-oval-tube heat exchanger.

Figures 6(a), 6(b), and 6(c) present the temperature contours in transverse planes for $\operatorname{Re}=1500$ and $\alpha=30^{\circ}$ with wing tip pointing downstream at $\mathrm{PR}=2,4$, and 6 , respectively, of the punched delta wings in the fin-andoval-tube heat exchanger. In general, the better mixing of the fluid temperature, produced by vortex flow and small vortices, is found for all PRs, especially behind the oval tubes (second, third, and fourth planes). The temperature contours in transverse planes of the wing tip pointing upstream at $\operatorname{Re}=1500, \alpha=30^{\circ}$, and PR $=2$ are presented in Figure 7. It is found that the heat transfer profile with the wing tip 


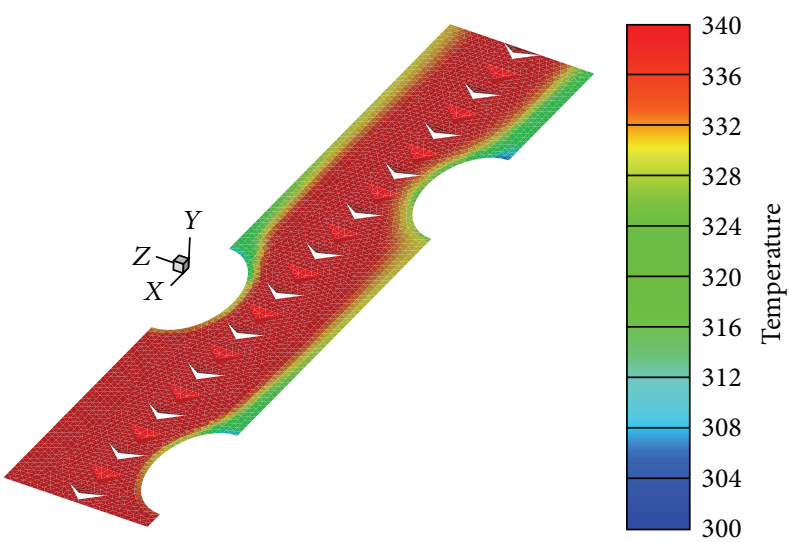

(a)

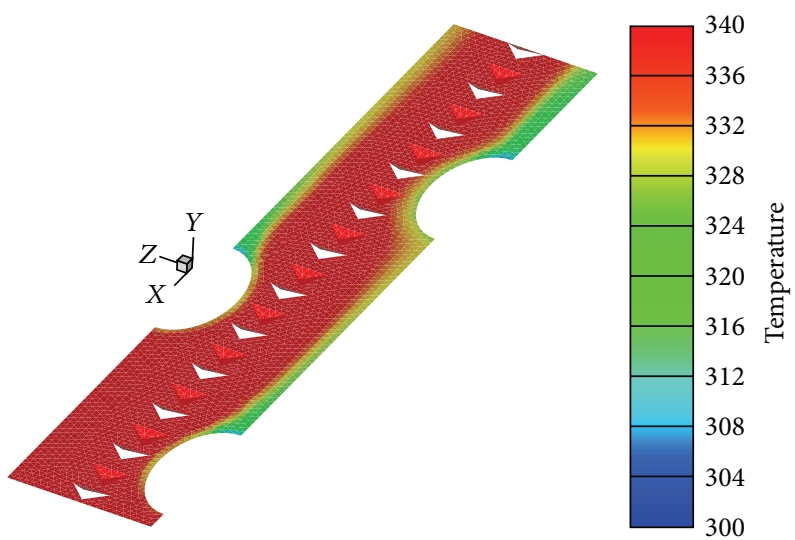

(b)

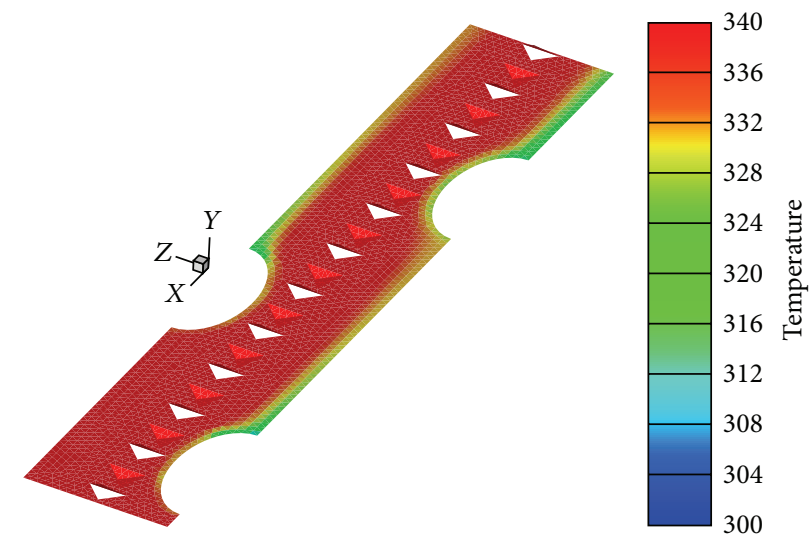

(c)

Figure 13: Temperature contours on the fin surface for (a) $\alpha=20^{\circ}$, (b) $\alpha=30^{\circ}$, and (c) $\alpha=45^{\circ}$ at $\mathrm{PR}=2, \operatorname{Re}=2000$, and $\alpha=30^{\circ}$ with wing tip pointing upstream.

pointing upstream is similar to that with the wing tip pointing downstream; and the better mixing of the fluid temperature is found behind the oval tubes. The temperature contours on the fin surface for $\mathrm{PR}=2,4$, and 6 at $\mathrm{Re}=1500$ and $\alpha=30^{\circ}$ with wing tip pointing downstream are reported in Figures $8(\mathrm{a}), 8(\mathrm{~b})$, and $8(\mathrm{c})$, respectively. The similar profile of the heat transfer is found for all PRs. The similar pattern of the temperature contours on the fin surface is found in case of the wing tip pointing upstream (see Figure 9).

The local Nusselt number contours with $\mathrm{PR}=2,4$, and 6 for $\operatorname{Re}=1500$ and $\alpha=30^{\circ}$ with wing tip pointing downstream are displayed in Figures 10(a), 10(b), and 10(c), respectively, while the wing tip pointing upstream at similar condition with $\mathrm{PR}=2$ is presented in Figure 11. Generally, the peak of the local Nusselt number is found at the leading curve of the oval tubes for all PR values for both wing tips pointing downstream and upstream. The presence of the oval tubes acts like a flow blockage and results in the impingement flow at leading curve of the tubes. The impingement of the fluid flow leads to a reduction in the thickness of thermal boundary layer on the tube walls, which enhances the heat transfer rates in the heat exchanger. The vortex flow, produced by the punched delta wings, helps promote the strength of the impinging flow.
Figures 12(a), 12(b), and 12(c) present the temperature contours on the fin surface for $\alpha=20^{\circ}, 30^{\circ}$, and $45^{\circ}$ at $\operatorname{Re}$ $=2000$ and $\mathrm{PR}=2$ with wing tip pointing downstream, respectively. The better mixing of the flow is found behind the oval tubes for all angles. The similar results are found in case of wing tip pointing upstream, shown in Figures 13(a), 13(b), and $13(\mathrm{c})$ for $\alpha=20^{\circ}, 30^{\circ}$, and $45^{\circ}$ at $\operatorname{Re}=2000$ and $\mathrm{PR}=2$, respectively. The heat transfer characteristic in terms of the local Nusselt number is depicted in Figures 14 and 15 for the wing tips pointing downstream and upstream, respectively. The leading curve of the oval tubes gives the best heat transfer augmentation for all cases.

\section{Performance Evaluation}

As the flow patterns and heat transfer characteristics for all cases are very close, the values of the Nusselt number $(\mathrm{Nu})$, Nusselt number ratio $\left(\mathrm{Nu} / \mathrm{Nu}_{0}\right)$, friction factor $(f)$, friction factor ratio $\left(f / f_{0}\right)$, and thermal enhancement factor (TEF) will be described to see the effects of the PRs and the punched angle on heat transfer, friction loss, and thermal performance. The performance evaluations for the punched delta wing in the fin-and-oval tube heat exchanger at $\operatorname{Re}=500-2500, \alpha=$ 


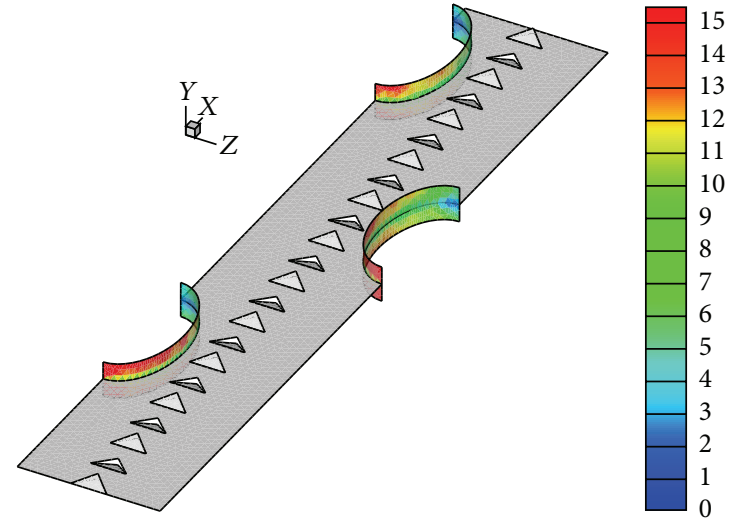

(a)

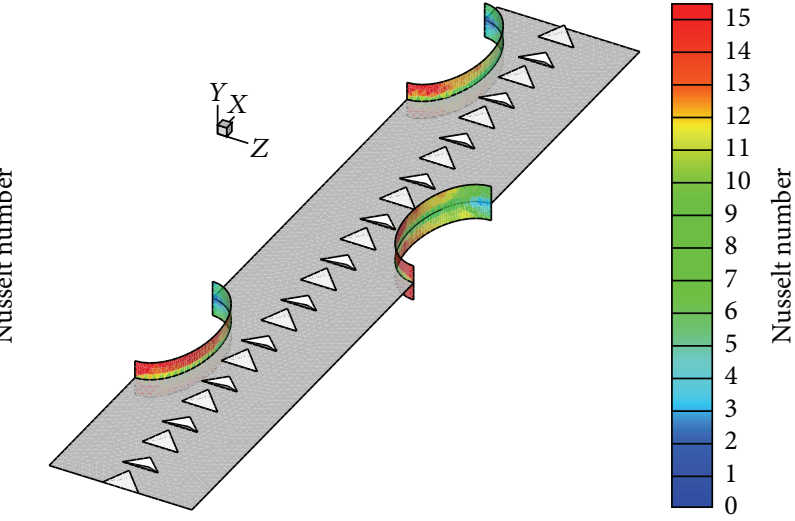

(b)

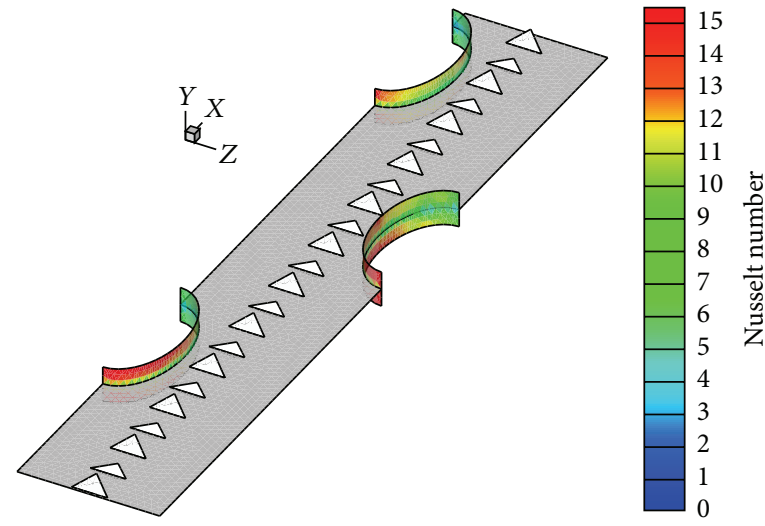

(c)

Figure 14: $\mathrm{Nu}_{x}$ contours on the fin surface for (a) $\alpha=20^{\circ}$, (b) $\alpha=30^{\circ}$, and (c) $\alpha=45^{\circ}$ at $\mathrm{PR}=2, \operatorname{Re}=2000$, and $\alpha=30^{\circ}$ with wing tip pointing downstream.

$20^{\circ}-45^{\circ}$, and $\mathrm{PR}=2-6$ with wing tips pointing downstream and upstream are presented in Figures 16-19.

In general, the increase in the Reynolds number leads to an increase in the Nusselt number but a decrease in the friction factor for all cases. The use of the punched delta wings in the fin-and-oval-tube heat exchanger results in an enhancement in both Nusselt number and friction factor over the plain fin or base case as displayed in terms of $\mathrm{Nu} / \mathrm{Nu}_{0}$ and $f / f_{0}$, which are higher than 1 .

Figures 16(a), 16(b), 16(c), 16(d), and 16(e) report the variations of $\mathrm{Nu}, \mathrm{Nu} / \mathrm{Nu}_{0}, f, f / f_{0}$, and TEF with the Reynolds number for $\alpha=30^{\circ}$ with wing tip pointing downstream at various $\mathrm{PR}$ values, respectively. $\mathrm{PR}=2$ provides the highest heat transfer rate, while $\mathrm{PR}=6$ gives the lowest value. The reduction in heat transfer rate is due to the rising $P R$. The maximum Nusselt number values are around 13.65, 13.53, $13.42,13.33$, and 13.22 for $\mathrm{PR}=2,3,4,5$, and 6, respectively, at $\mathrm{Re}=2500 . \mathrm{PR}=2$ gives higher heat transfer rates than $\mathrm{PR}=6$ around $3.15 \%$. The punched delta wings produce the heat transfer rate around 1.02-1.22 times higher than the plain fin (see Figure 16(b)). It can be concluded that the use of the punched delta wings generates vortex flow in the fin-andoval-tube heat exchanger, which helps increase the impinging strength of the fluid flow at the leading curve of the oval tube walls. The impingement of the flow can decrease the thermal boundary layer thickness that helps improve heat transfer rate in the heating system. The highest friction loss is found at $\mathrm{PR}=2$, while $\mathrm{PR}=5$ and 6 give the lowest value. The maximum friction factor is around 1.82, 1.63, 1.55, 1.51, and 1.51 times higher than the plain fin for $P R=2,3,4,5$, and 6 , respectively. The friction factor for using the punched delta wings at $\alpha=30^{\circ}$ with wing tip pointing downstream is found in range of 1.41-1.82 times higher than the plain fin for $\operatorname{Re}=500-2500$. As the numerical results discussed above, we found that the use of the punched delta wing leads to an augmentation in both heat transfer and friction loss in the heating system; therefore TEF is used to evaluate the thermal performance (see Figure 16(e)). Considering the current model as the rectangular channel heat exchanger [19], TEF is calculated from both $\mathrm{Nu} / \mathrm{Nu}_{0}$ and $f / f_{0}$. The TEF of the $30^{\circ} \mathrm{V}$-downstream wing in the fin-and-oval-tube heat exchanger is around $0.86-1.05$ at $\mathrm{Re}=500$ and $\mathrm{PR}=4$. Although $\mathrm{PR}=2$ provides the maximum heat transfer rate and also gives very enlarge pressure loss, the optimum point between the enhancing heat transfer and friction factor is found at $\mathrm{PR}=4$.

Figures 17(a), 17(b), 17(c), and 17(d) display the variations of $\mathrm{Nu}, \mathrm{Nu} / \mathrm{Nu}_{0}, f, f / f_{0}$, and TEF, respectively, with the 


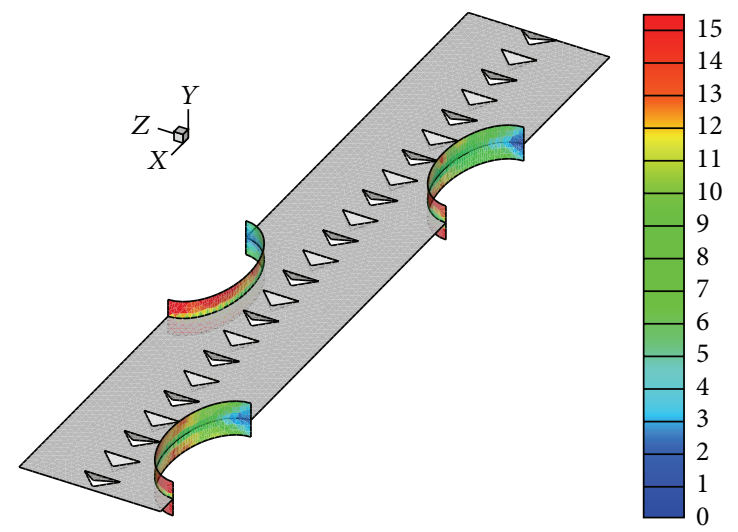

(a)

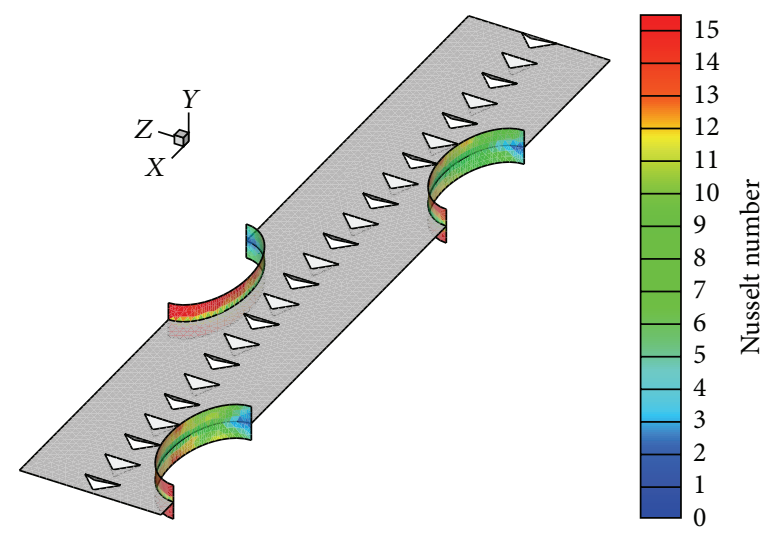

(b)

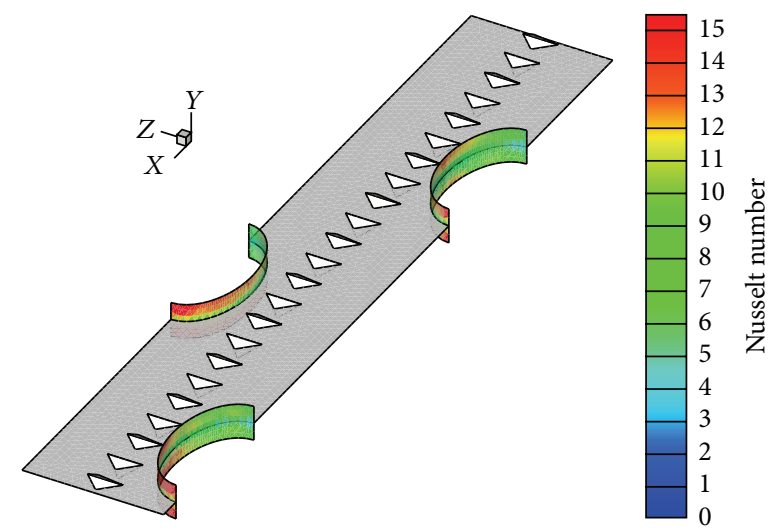

(c)

FiguRE 15: $\mathrm{Nu}_{x}$ contours on the fin surface for (a) $\alpha=20^{\circ}$, (b) $\alpha=30^{\circ}$, and (c) $\alpha=45^{\circ}$ at $\mathrm{PR}=2, \mathrm{Re}=2000$, and $\alpha=30^{\circ}$ with wing tip pointing upstream.

Reynolds number for the punched delta wings in the finand-oval-tube heat exchanger at $\alpha=30^{\circ}$ with the wing tip pointing upstream of various PRs. In general, the trends of the numerical results are found similarly as the wing tip pointing downstream. The enhancements of heat transfer and friction factor are around 1.01-1.20 and 1.37-1.77 times higher than the base case, respectively. The maximum TEF is around 1.03 for $\mathrm{PR}=4$ at the low Reynolds number, $\mathrm{Re}=500$.

The wing tip pointing downstream gives slightly better heat transfer rate and thermal performance than the upstream case. The wing tip pointing downstream also provides slightly higher friction loss than the upstream case. The variations of the PRs for the punched delta wings in the fin-and-oval-tube heat exchanger have a gentle effect for heat transfer, pressure loss, and thermal performance.

Figures 18(a), 18(b), and 18(c) present the variations of $\mathrm{Nu}, \mathrm{Nu} / \mathrm{Nu}_{0}, f, f / f_{0}$, and TEF for $\mathrm{PR}=2$ with the wing tip pointing downstream, respectively, at various delta wing angles. The use of the punched delta wings with various punched angles provides higher heat transfer rate than the baseline case for all Reynolds numbers. $\alpha=30^{\circ}$ gives the highest heat transfer rate, while lowest value is found in the case of $\alpha=20^{\circ} . \alpha=20^{\circ}, 30^{\circ}$, and $45^{\circ}$ provide a higher heat transfer rate than the plain fin around 1.18, 1.22, and 1.20 times, respectively. The reason of this may be the fact that $\alpha=30^{\circ}$ can produce the optimum helical pitch length of the longitudinal vortex flow through the test section. The best helical pitch length results in the increase in impinging strength of the fluid flow on the leading curve of the oval tube wall that helps improve the heat transfer rate and thermal performance. As shown in Figures 18(c) and 18(d), for $\alpha=$ $45^{\circ}$, the pressure drop is very large. $\alpha=45^{\circ}$ shows the highest friction factor, while $\alpha=20^{\circ}$ presents the reverse trend. $\alpha$ $=20^{\circ}, 30^{\circ}$, and $45^{\circ}$ perform higher friction factor than the smooth fin around 1.53, 1.8, and 2.65 times, respectively, at $\operatorname{Re}=2500 . \alpha=45^{\circ}$ provides a higher friction factor ratio than $\alpha=20^{\circ}$ and $30^{\circ}$ around $32.08 \%$ and $42.45 \%$, respectively. Considering the cross-sectional area ( $y-z$ plane), $\alpha=45^{\circ}$ is the largest flow blockage area in comparison with other angles; therefore $\alpha=45^{\circ}$ gives the highest friction factor value. The optimum TEF is found around 1.04 at $\alpha=20^{\circ}$ and $\operatorname{Re}=$ 500 (see Figure 18(e)). Due to the very enlarge pressure loss which was created by $\alpha=45^{\circ}$, TEF in this case is found to be the lowest value.

For the effects of the punched angles, the similar trends for $\mathrm{Nu}, \mathrm{Nu} / \mathrm{Nu}_{0}, f, f / f_{0}$, and TEF are found in the case of the wing tip pointing upstream as depicted in Figures 19(a), 19(b), 19(c), 19(d), and 19(e), respectively. The augmentations of the 


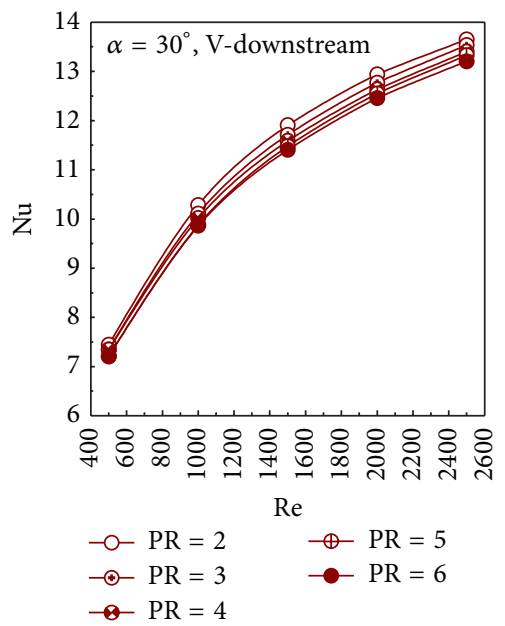

(a)

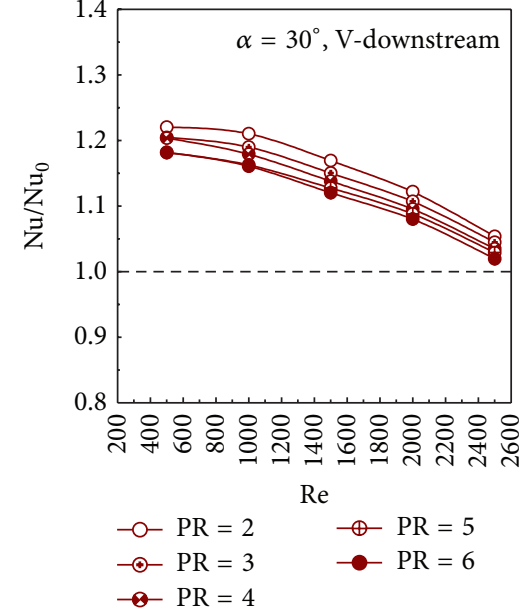

(b)

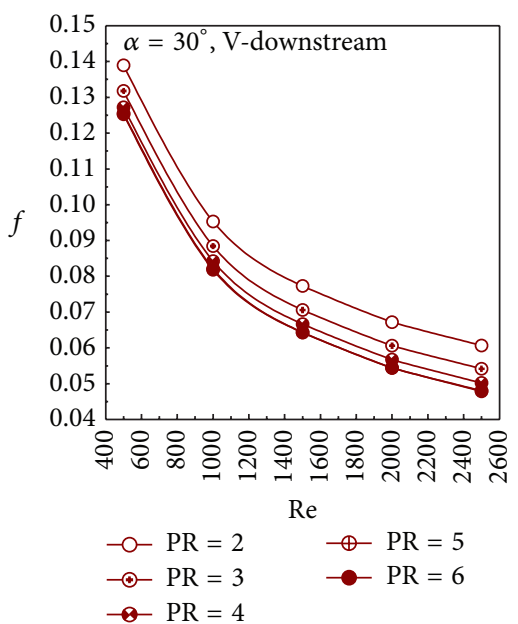

(c)

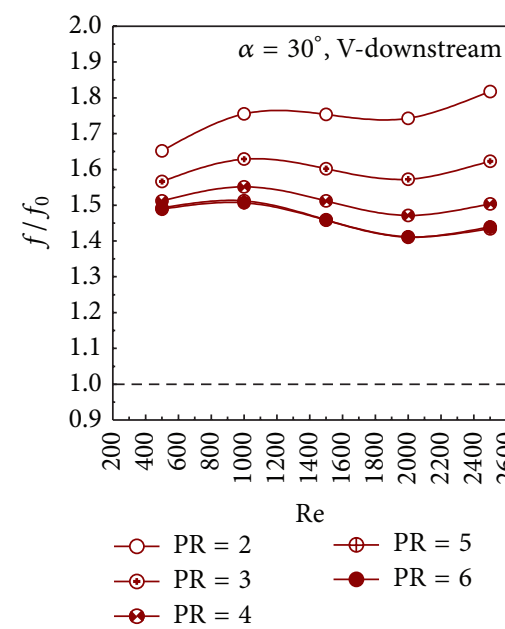

(d)

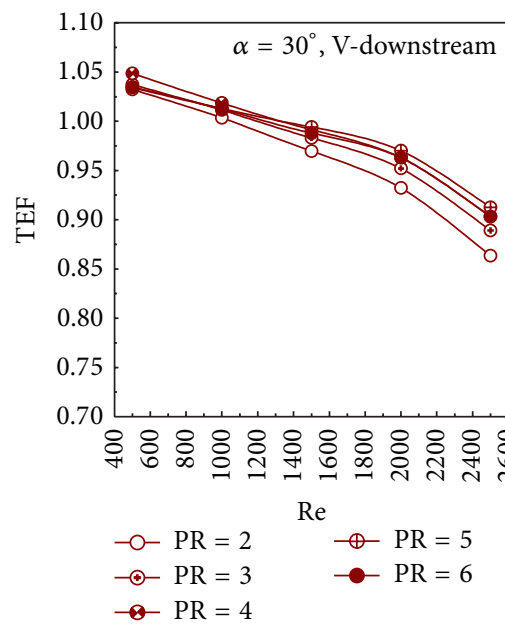

(e)

Figure 16: (a) Nu versus $\mathrm{Re}$, (b) $\mathrm{Nu} / \mathrm{Nu}_{0}$ versus Re, (c) $f$ versus $\mathrm{Re}$, (d) $f / f_{0}$ versus $\mathrm{Re}$, and (e) TEF versus Re at various PR for $\alpha=30^{\circ}$ with wing tip pointing downstream.

heat transfer rate and friction factor are around 1.01-1.20 and 1.40-2.40 times higher than the baseline case, respectively, for wing tip pointing upstream: $\mathrm{Re}=500-2500, \mathrm{PR}=2$, and $\alpha=$ $20^{\circ}, 30^{\circ}$, and $45^{\circ}$. The optimum TEF about 1.02 is found at Re $=500$ and $\alpha=20^{\circ}$.

\section{Conclusion}

The numerical investigations on heat transfer, friction loss, and thermal performance of the punched delta wings in the fin-and-oval-tube heat exchanger are presented for $\mathrm{Re}=500-$ 2500. The influences of the punched angles, PRs, and the flow directions are investigated. The numerical results are reported in terms of the flow patterns, heat transfer characteristics, and performance evaluations and are also compared with the plain fin with no punched delta wing. The main findings from the current investigations are as follows:

(i) The punched delta wing in the fin-and-the-oval-tube heat exchanger leads to an increase of both heat transfer and friction factor. The punched delta wing can generate the vortex flow that helps increase the impinging strength of the test fluid on the leading curve of the oval tube. Moreover, the disturbed thermal boundary layer on the fin surface is also a reason for heat transfer augmentation. However, the presence of the punched delta wings, which is reducing the flow area, results in the rise of the pressure loss in the heating system.

(ii) The use of the punched delta wings leads to an increase of both the Nusselt number and friction factor higher than the plain fin for all cases. In range studied, the enhancing heat transfer rates and friction factor are found to be around 1.01-1.22 and 1.37-2.65 times higher than the smooth fin, respectively. The optimum thermal enhancement factor is around 1.05 at low Reynolds number, $\mathrm{Re}=500$.

(iii) Effect of PR, the rising PR, leads to a slight decrease of both heat transfer and pressure loss. $\mathrm{PR}=2$ provides 


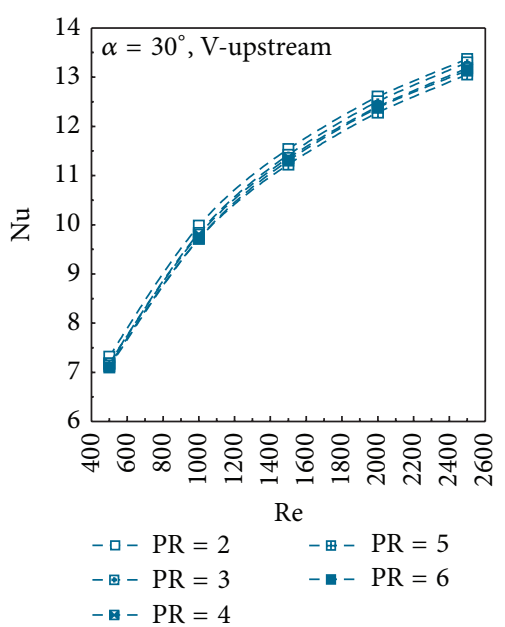

(a)

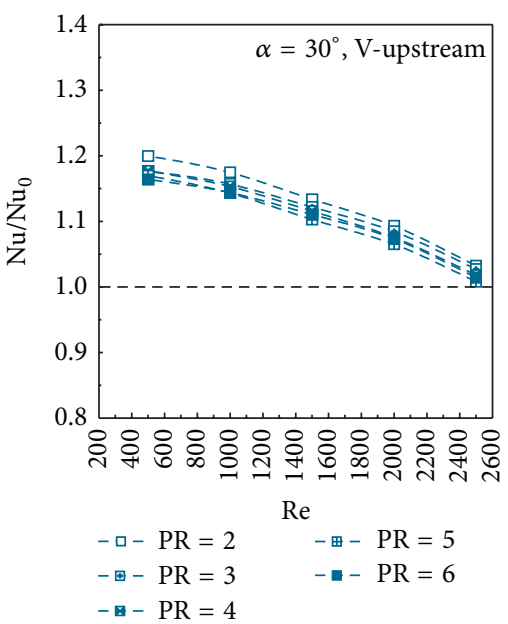

(b)

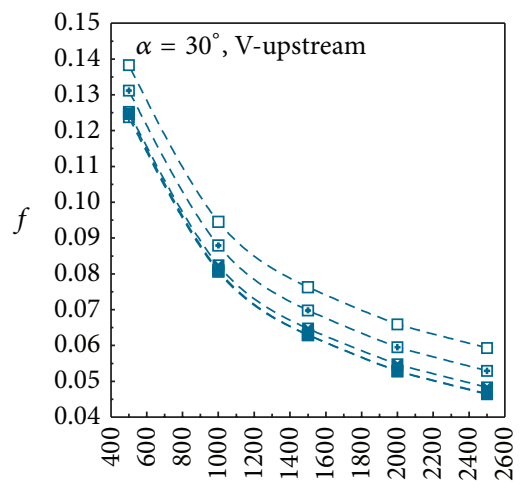

\begin{tabular}{lrl} 
& \multicolumn{2}{l}{ Re } \\
- - $\mathrm{PR}=2$ & - $-\mathrm{PR}=5$ \\
- $-\mathrm{PR}=3$ & - - $\mathrm{PR}=6$ \\
- - $\mathrm{PR}=4$ &
\end{tabular}

(c)

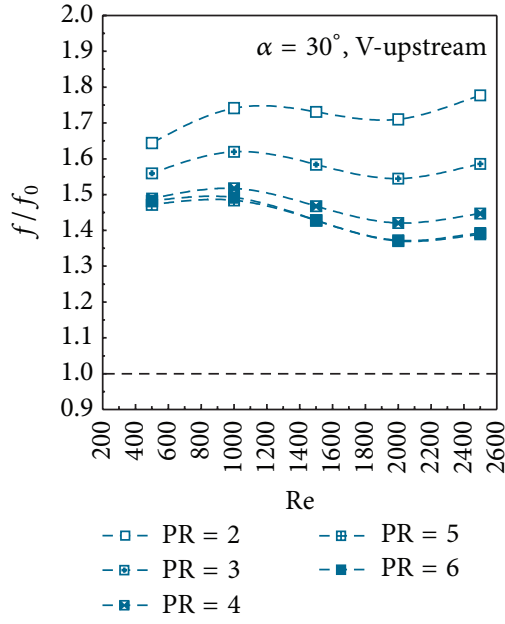

(d)

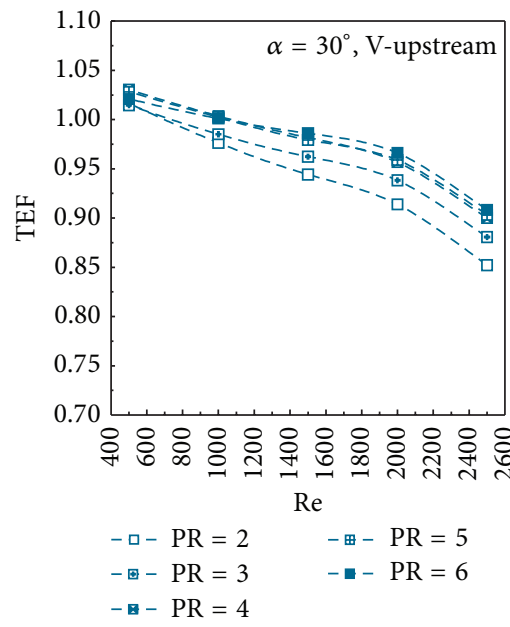

(e)

Figure 17: (a) Nu versus Re, (b) Nu/Nu${ }_{0}$ versus Re, (c) $f$ versus Re, (d) $f / f_{0}$ versus Re, and (e) TEF versus Re at various PR for $\alpha=30^{\circ}$ with wing tip pointing upstream.

the highest heat transfer rate and friction loss, while $\mathrm{PR}=6$ performs the lowest values. $\mathrm{PR}=2$ can produce the highest vortex strength, which enhances impinging potency of the fluid flow on the oval tube wall.

(iv) Effect of flow direction with the wing tip pointing downstream gives slightly higher heat transfer rate and friction loss than the wing tip pointing upstream.

(v) $\alpha=30^{\circ}$ can create the optimum length of the longitudinal vortex flow, which helps augment the strength of the flow impingement on the tube walls. $\alpha=20^{\circ}$ provides the lowest heat transfer rate but helps reduce the pressure loss of the heat exchanger. The maximum friction factor is found at case of $\alpha=45^{\circ}$, while the lowest value appears in case of $\alpha=20^{\circ}$. The optimum TEF for $\alpha=20^{\circ}$ and $30^{\circ}$ is found very close, while $\alpha$ $=45^{\circ}$ produced the lowest trend (almost values lower than 1). (vi) In comparison with [20], it is found that the wing type vortex generators can help reduce the pressure loss in the fin-and-oval-tube heat exchanger with remaining very close heat transfer and thermal performance. The maximum friction factor is around 2.65 and 4.40 times higher than the smooth tube for the wing (current investigation) and winglet [20], respectively. Moreover, the use of the wing is more appropriate for low Reynolds number $(\operatorname{Re} \leq 500)$, while the winglet is suitable for $\mathrm{Re} \cong 2000$.

\section{Nomenclature}

a: Wing spacing $(\mathrm{m})$

A: Total heat transfer surface area $\left(\mathrm{m}^{2}\right)$

$A_{c}$ : Minimum flow area $\left(\mathrm{m}^{2}\right)$

$B$ : Channel width (m)

$D_{h}$ : Hydraulic diameter $(\mathrm{m}),\left(=4 A_{c} L / A\right)$

$f$ : Friction factor 

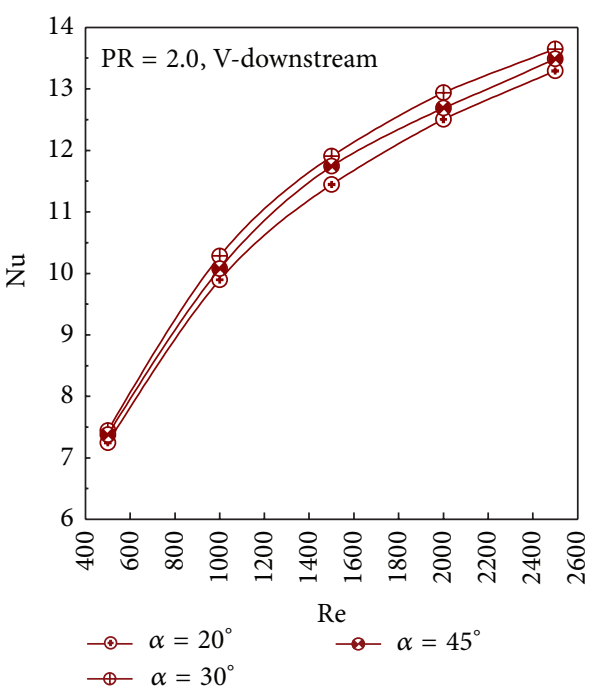

(a)

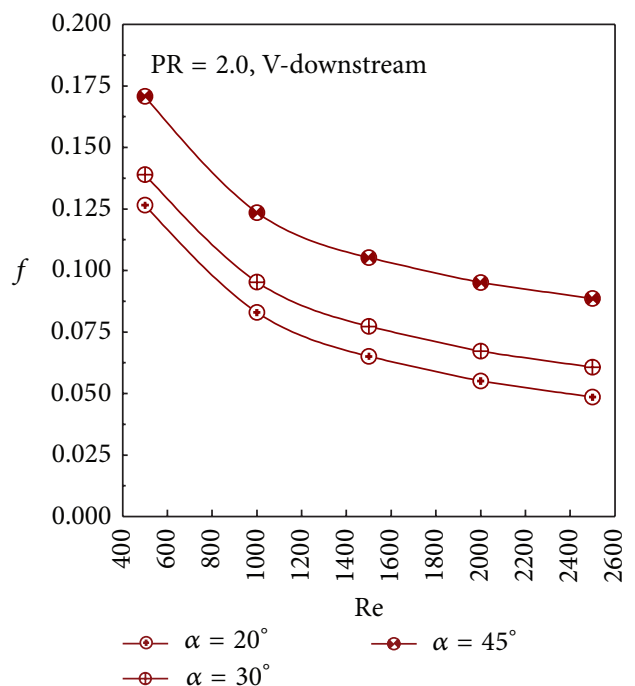

(c)

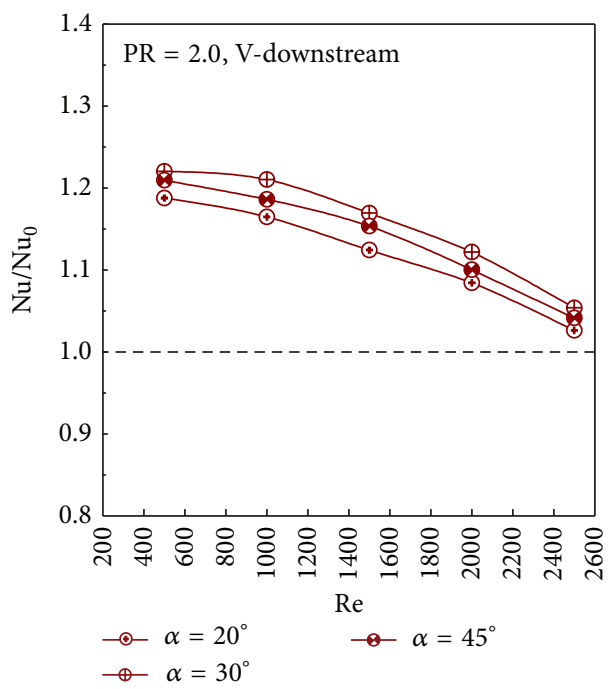

(b)

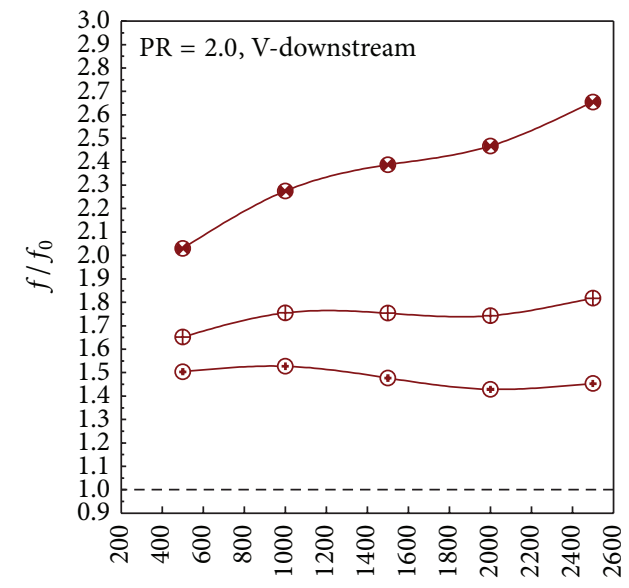

$\operatorname{Re}$

$$
\rightarrow \alpha=20^{\circ} \rightarrow \alpha=45^{\circ}
$$

(d)

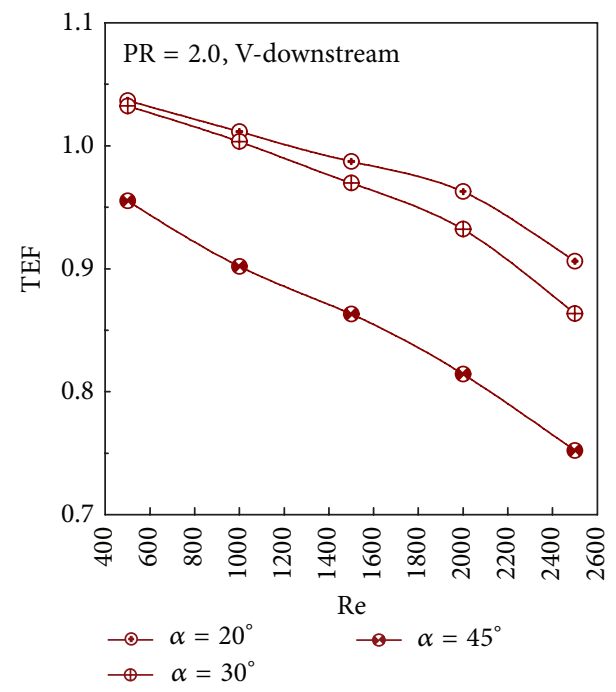

(e)

Figure 18: (a) Nu versus Re, (b) Nu/Nu $\mathrm{Nu}_{0}$ versus Re, (c) $f$ versus $\mathrm{Re}$, (d) $f / f_{0}$ versus $\mathrm{Re}$, and (e) TEF versus Re at various $\alpha$ for PR $=2$ with wing tip pointing downstream. 


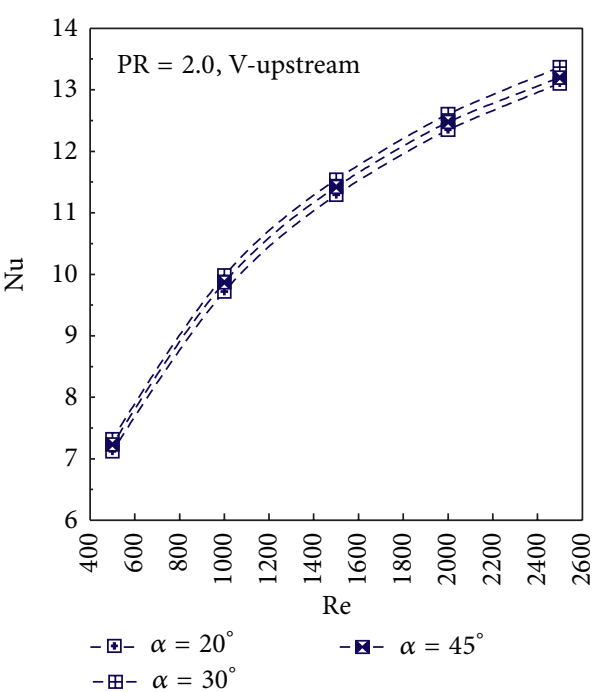

(a)

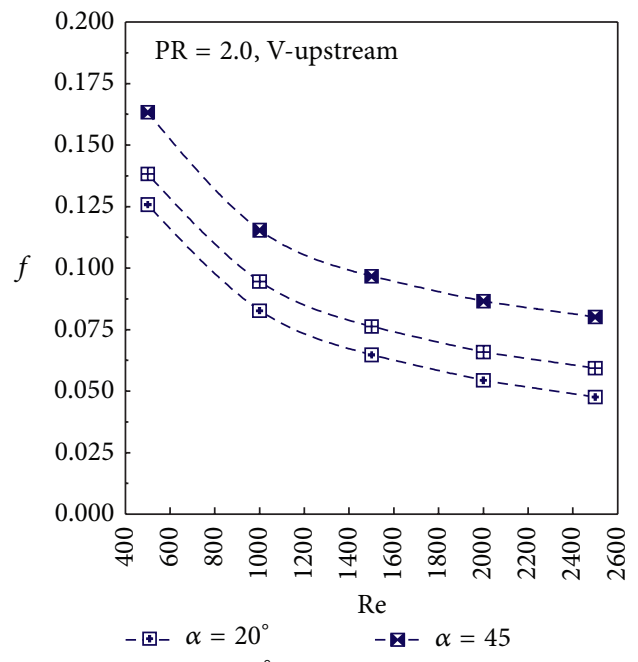

$-\boxplus-\alpha=30^{\circ}$

(c)

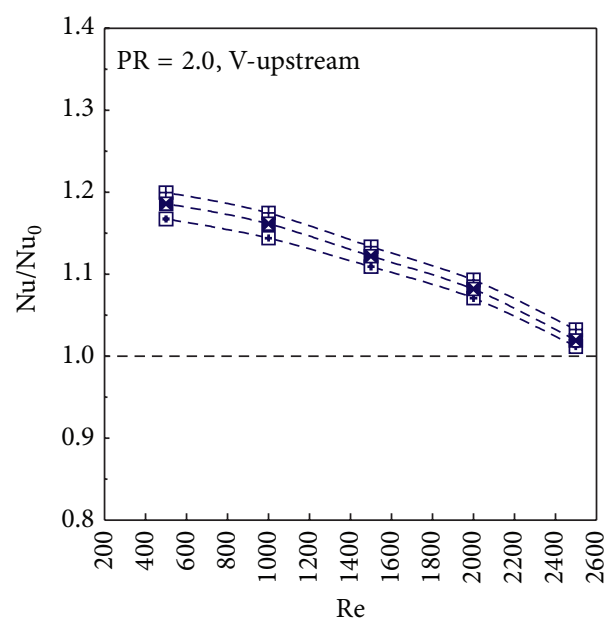

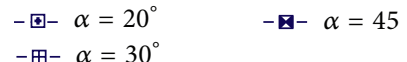

(b)

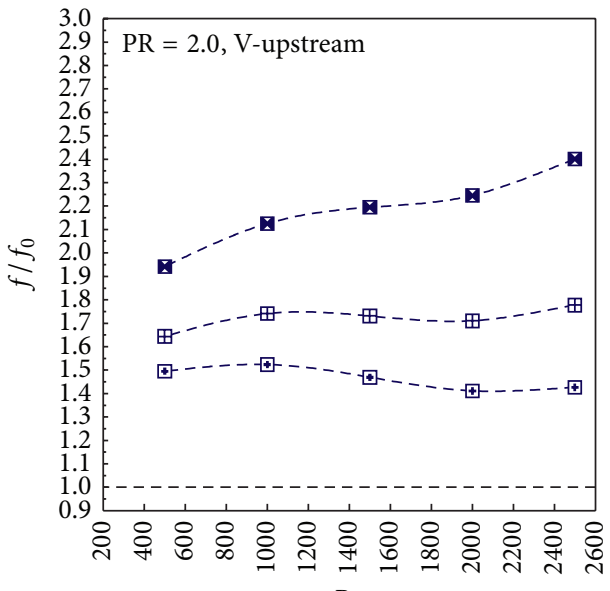

$\operatorname{Re}$

$$
\text { - } \square-\alpha=20^{\circ}
$$$$
\text { - } ⿴ 囗 十-\alpha=30^{\circ}
$$

(d)

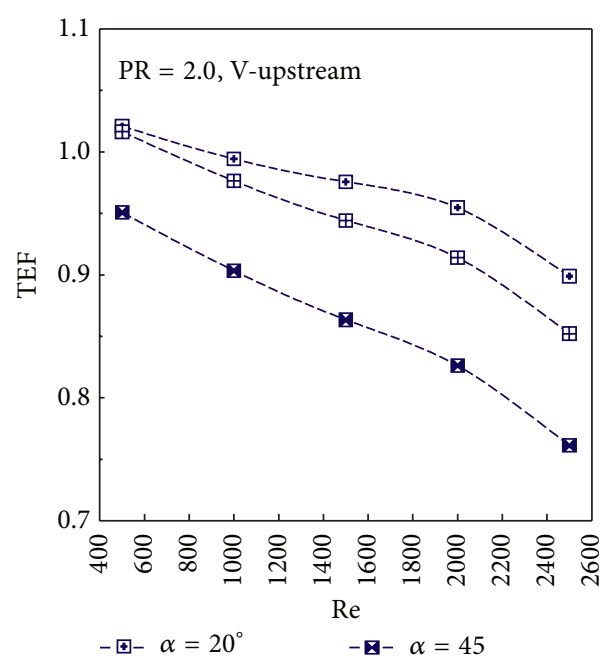

$$
\begin{array}{ll}
\text { - }-\alpha=20^{\circ} & -\mathbf{\square}-\alpha=45 \\
\text { - }-\alpha-\alpha=30^{\circ} &
\end{array}
$$

(e)

Figure 19: (a) Nu versus Re, (b) $\mathrm{Nu} / \mathrm{Nu}_{0}$ versus Re, (c) $f$ versus Re, (d) $f / f_{0}$ versus $\mathrm{Re}$, and (e) TEF versus Re at various $\alpha$ for PR $=2$ with wing tip pointing upstream. 


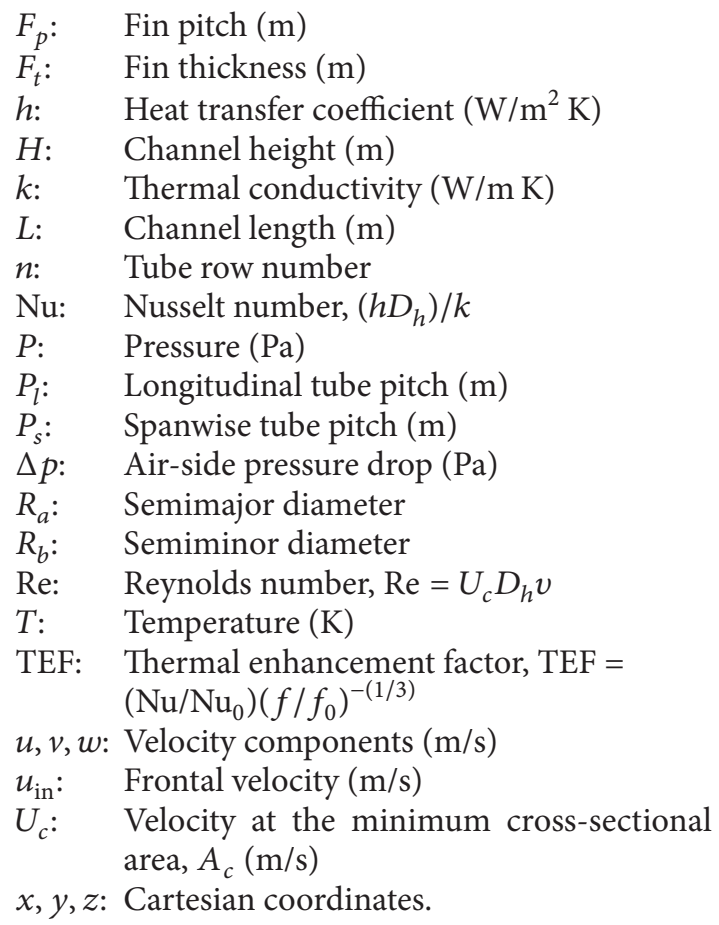

\section{Greek Symbols}

$\alpha$ : Punched delta wing angle

$\mu$ : Dynamic viscosity (Pas)

$v$ : Kinematic viscosity $\left(\mathrm{m}^{2} / \mathrm{s}\right)$

$\rho$ : Density $\left(\mathrm{kg} / \mathrm{m}^{3}\right)$

$k$ : Thermal conductivity $(\mathrm{W} / \mathrm{m} \mathrm{K})$.

\section{Subscripts}

in: Inlet parameter

$w$ : Wall

0: Smooth fin.

\section{Conflict of Interests}

The author declares that there is no conflict of interests regarding the publication of this paper.

\section{Acknowledgments}

This researcher was funded by College of Industrial Technology, King Mongkut's University of Technology North Bangkok, Thailand. The researchers would like to thank Assoc. Professor Dr. Pongjet Promvonge for suggestions.

\section{References}

[1] L. Li, X. Du, Y. Zhang, L. Yang, and Y. Yang, "Numerical simulation on flow and heat transfer of fin-and-tube heat exchanger with longitudinal vortex generators," International Journal of Thermal Sciences, vol. 92, pp. 85-96, 2015.

[2] B. Gong, L.-B. Wang, and Z.-M. Lin, "Heat transfer characteristics of a circular tube bank fin heat exchanger with fins punched curve rectangular vortex generators in the wake regions of the tubes," Applied Thermal Engineering, vol. 75, pp. 224-238, 2015.

[3] B. Delač, A. Trp, and K. Lenić, "Numerical investigation of heat transfer enhancement in a fin and tube heat exchanger using vortex generators," International Journal of Heat and Mass Transfer, vol. 78, pp. 662-669, 2014.

[4] B. Lotfi, M. Zeng, B. Sundén, and Q. Wang, “3D numerical investigation of flow and heat transfer characteristics in smooth wavy fin-and-elliptical tube heat exchangers using new type vortex generators," Energy, vol. 73, pp. 233-257, 2014.

[5] A. A. Gholami, M. A. Wahid, and H. A. Mohammed, "Heat transfer enhancement and pressure drop for fin-and-tube compact heat exchangers with wavy rectangular winglet-type vortex generators," International Communications in Heat and Mass Transfer, vol. 54, pp. 132-140, 2014.

[6] J. Y. Jang, L. F. Hsu, and J. S. Leu, "Optimization of the span angle and location of vortex generators in a plate-fin and tube heat exchanger," International Journal of Heat and Mass Transfer, vol. 67, pp. 432-444, 2013.

[7] Y. L. He, P. Chu, W. Q. Tao, Y. W. Zhang, and T. Xie, "Analysis of heat transfer and pressure drop for fin-and-tube heat exchangers with rectangular winglet-type vortex generators," Applied Thermal Engineering, vol. 61, no. 2, pp. 770-783, 2013.

[8] P. Saha, G. Biswas, and S. Sarkar, "Comparison of winglettype vortex generators periodically deployed in a plate-fin heat exchanger-a synergy based analysis," International Journal of Heat and Mass Transfer, vol. 74, pp. 292-305, 2014.

[9] X. Du, L. Feng, L. Li, L. Yang, and Y. Yang, "Heat transfer enhancement of wavy finned flat tube by punched longitudinal vortex generators," International Journal of Heat and Mass Transfer, vol. 75, pp. 368-380, 2014.

[10] H. Huisseune, C. T'Joen, P. D. Jaeger, B. Ameel, S. D. Schampheleire, and M. D. Paepe, "Performance enhancement of a louvered fin heat exchanger by using delta winglet vortex generators," International Journal of Heat and Mass Transfer, vol. 56, no. 1-2, pp. 475-487, 2013.

[11] J. Li, S. Wang, J. Chen, and Y.-G. Lei, "Numerical study on a slit fin-and-tube heat exchanger with longitudinal vortex generators," International Journal of Heat and Mass Transfer, vol. 54, no. 9-10, pp. 1743-1751, 2011.

[12] A. Lemouedda, M. Breuer, E. Franz, T. Botsch, and A. Delgado, "Optimization of the angle of attack of delta-winglet vortex generators in a plate-fin-and-tube heat exchanger," International Journal of Heat and Mass Transfer, vol. 53, no. 23-24, pp. 53865399, 2010.

[13] X. Du, L. Feng, Y. Yang, and L. Yang, "Experimental study on heat transfer enhancement of wavy finned flat tube with longitudinal vortex generators," Applied Thermal Engineering, vol. 50, no. 1, pp. 55-62, 2013.

[14] P. Chu, Y. L. He, Y. G. Lei, L. T. Tian, and R. Li, “Three-dimensional numerical study on fin-and-oval-tube heat exchanger with longitudinal vortex generators," Applied Thermal Engineering, vol. 29, no. 5-6, pp. 859-876, 2009.

[15] A. Joardar and A. M. Jacobi, "Heat transfer enhancement by winglet-type vortex generator arrays in compact plain-fin-andtube heat exchangers," International Journal of Refrigeration, vol. 31, no. 1, pp. 87-97, 2008.

[16] M. J. Li, W. J. Zhou, J. F. Zhang, J. F. Fan, Y. L. He, and W. Q. Tao, "Heat transfer and pressure performance of a plain fin with radiantly arranged winglets around each tube in fin-and-tube heat transfer surface," International Journal of Heat and Mass Transfer, vol. 70, pp. 734-744, 2014. 
[17] L. Tian, Y. He, Y. Tao, and W. Tao, "A comparative study on the air-side performance of wavy fin-and-tube heat exchanger with punched delta winglets in staggered and in-line arrangements," International Journal of Thermal Sciences, vol. 48, no. 9, pp. 1765-1776, 2009.

[18] M. J. Lawson and K. A. Thole, "Heat transfer augmentation along the tube wall of a louvered fin heat exchanger using practical delta winglets," International Journal of Heat and Mass Transfer, vol. 51, no. 9-10, pp. 2346-2360, 2008.

[19] P. Sriromreun, C. Thianpong, and P. Promvonge, "Experimental and numerical study on heat transfer enhancement in a channel with Z-shaped baffles," International Communications in Heat and Mass Transfer, vol. 39, no. 7, pp. 945-952, 2012.

[20] A. Boonloi and W. Jedasadaratanachai, "3D Numerical analysis on flow configurations and heat transfer characteristics for fin-and-oval-tube heat exchanger with V-Downstream delta winglet vortex generators," Frontiers in Heat and Mass Transfer, vol. 5, article 9, 2014. 

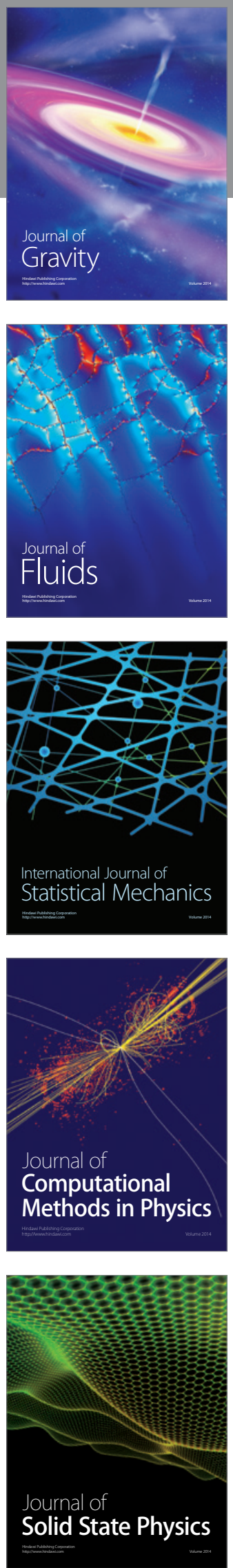

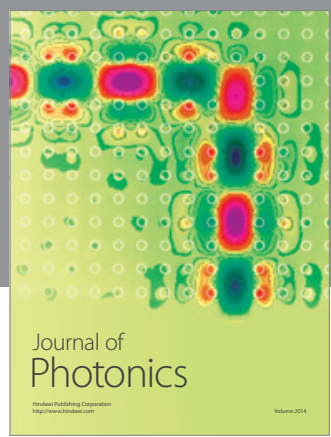

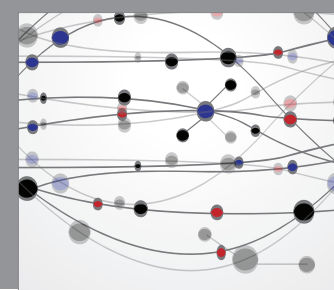

The Scientific World Journal

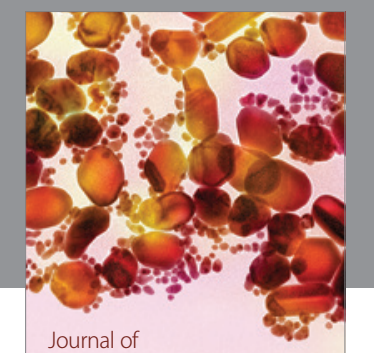

Soft Matter
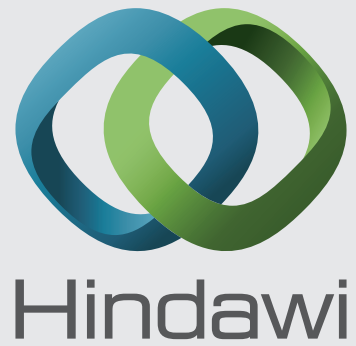

Submit your manuscripts at

http://www.hindawi.com
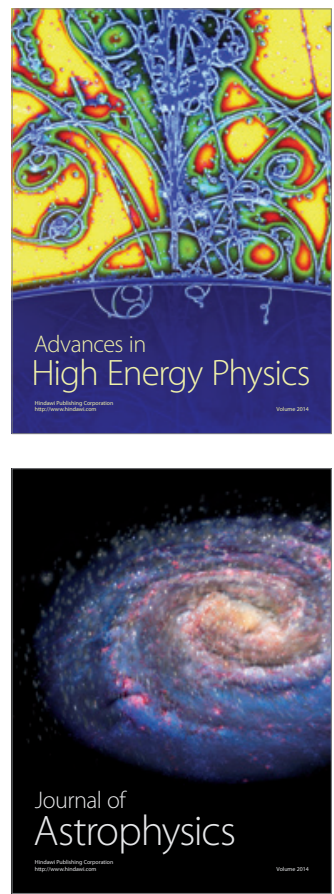
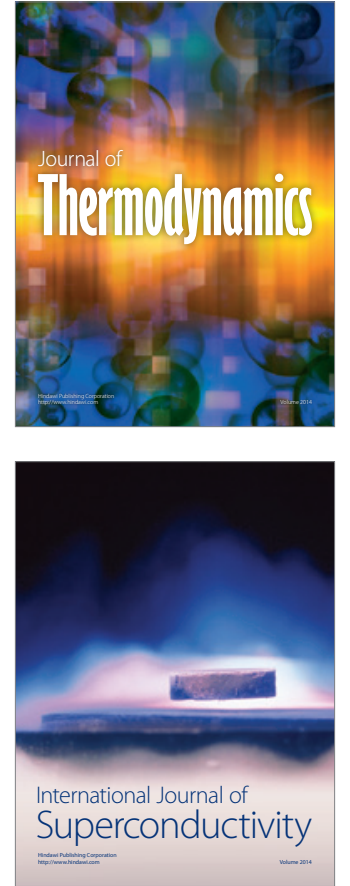
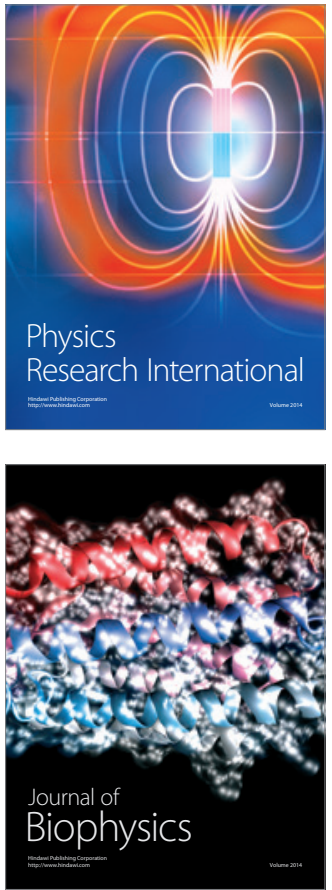
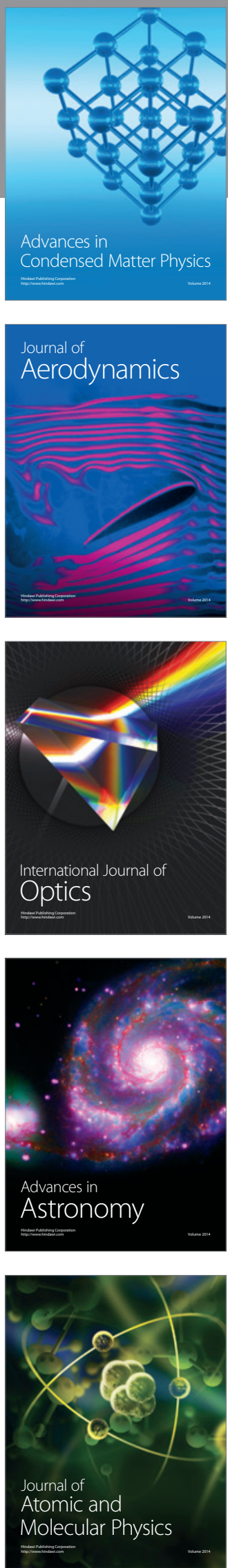